\title{
Repression in Residential Youth Care: A Scoping Review
}

\author{
S. de Valk ${ }^{1}$ • C. Kuiper ${ }^{1,2}$ - G. H. P. van der Helm ${ }^{1}$ A. J. J. A. Maas ${ }^{3}$. \\ G. J. J. M. Stams ${ }^{4}$
}

Received: 10 March 2016/Accepted: 14 April 2016/Published online: 28 April 2016

(C) Springer International Publishing 2016

\begin{abstract}
Residential youth care settings should provide youth with safe environments where they are supported and treated. However, there are aspects of residential youth care that threaten its effectiveness, and which may also violate children's rights. Staff members exercise power over the youth, which can be abused to coerce, punish, or limit the autonomy of youth. Currently, the harmful behavior of staff includes repression through such acts as harsh and unfair control, punishment, and lack of autonomy granting. However, research on the exact nature of repression is lacking, which hampers empirical research on repression in residential youth care, and makes it difficult for residential settings to recognize repression and take the right corrective measures. A scoping review of the available literature is conducted from a humanistic, social psychological, and organizational perspective to examine the nature of repression and to provide a valid definition and its antecedents. This article offers implications for preventing, recognizing, and diminishing repression in residential youth care.
\end{abstract}

S. de Valk

valk.de.s@hsleiden.nl

1 Youth Expert Centre, University of Applied Sciences, Leiden, Zernikedreef 11, 2333 CK Leiden, The Netherlands

2 Horizon Youth Care and Education, Mozartlaan 150, 3055 KM Rotterdam, The Netherlands

3 Department of Organization and Personnel Management, Erasmus University, Rotterdam, Burgemeester Oudlaan 150, Mandeville Building, 3062 PA Rotterdam, The Netherlands

4 Department of Forensic Child and Youth Care Sciences, University of Amsterdam, Roeterseilandcampus, Building D, Nieuwe Achtergracht 166, 1018 WV Amsterdam, The Netherlands
Keywords Repression - Residential youth care - Staff · Power · Autonomy $\cdot$ Coercion

\section{Introduction}

Residential youth care institutions offer a treatment environment for children and adolescents who show serious psychiatric or behavioral problems. Two meta-analyses (De Swart et al. 2012; Strijbosch et al. 2015) showed that residential care and treatment can be effective. Children and adolescents ("youth") can react positively to treatment in institutional care and, in general, improve their psychological wellbeing (Knorth et al. 2008). However, nontherapeutic aspects of the institutions threaten the effectiveness of treatment inside residential youth care institutions. For example, staff may abuse the inevitable power over youth (Souverein et al. 2013), or staff may use inappropriate punishment as a behavioral consequence (De Valk et al. 2015). Furthermore, there are examples of serious violations of children's rights inside these settings (Browne 2009; Colton 2002; Höfte et al. 2012). In these cases, a stay in residential youth care institutions can be more harmful than effective in diminishing psychiatric or behavioral problems of youth.

Residential youth care takes place in group living facilities with approximately $8-12$ youth together in one living group. Normally, the youth are treated by trained psychiatric nurses or social workers who support them in all aspects of their stay. The goal of the treatment is to prepare youth to return to society, which-depending on the age and the needs of the youth-can differ from returning to their parents or other network members, to transferring to an assisted living environment. Youth are admitted to a residential facility because they are a danger 
to others or themselves, or they must be protected from their environment. The majority of these youth have a psychiatric or behavioral disorder deemed to require specialist attention (Anckarsäter et al. 2007; Colins et al. 2010; Fazel et al. 2008). Youth are also separated from their parents when they have committed a crime and are, consequently, imprisoned. The admission to residential institutions (either by civil or criminal law placement) is mostly involuntary. However, this mandatory admission is allowed, as exemplified by the United Nations Convention on the Rights of the Child (UNCRC 1992, article 9.1), as long as it is in the best interest of the child:

States Parties shall ensure that a child shall not be separated from his or her parents against their will, except when competent authorities subject to judicial review determine, in accordance with applicable law and procedures, that such separation is necessary for the best interests of the child.

Although this article allows for involuntary admission, there are aspects of residential institutions that threaten the effectiveness of residential care, and may also violate children's rights. Erving Goffman (Goffman 1961) was the first sociologist to describe residential settings as total institutions where patients are subjected to the power of the institution, limiting the residents' freedom of choice. In these total institutions, living, education, and leisure are inseparable, while individuality and privacy are restricted. An essential aspect of residential institutions is the physical environment that limits departure from the facility and social interaction with the outside world (Goffman 1961). Furthermore, youth are under constant supervision, and can never be certain of what is deemed pertinent to reports and assessments (Crewe 2009).

The power that staff members use to regulate the youth encompasses several risks. First, powerful people are more likely to engage in moral hypocrisy than those persons who lack power (Lammers et al. 2010). Furthermore, the powerful judge their own moral transgressions to be more acceptable than other person's moral transgressions. In a study by Lammers and Stapel (2011), it was found that power increases dehumanization-stripping experience or agency from youth (Haque and Waytz 2012; Haslam 2006). Dehumanization, by its innate tendency to downplay consequences, makes it easier to render difficult decisions. Thus, the power imbalance between youth and staff members may lead the latter to act in ways that youth may experience as unfair, or may even put a youth at harm. In the Stanford Prison Experiment, the claim was made that the power inherent to the role of guard inevitably led to brutality (Haney et al. 1973). Current day, physical brutality in prison is far less common than it was decades ago, but the misuse of so-called "soft power" can have consequences that are just as profound (Crewe 2009). Nye (2004) defines soft power as the ability to achieve one's ends through persuasion and attraction, as opposed to coercion or payment ("hard power").

A staff's power may be apparent in the way they try to modify the behavior of youth. Studies describe various examples of punishment directed to modify behavior inside prison (Akers 1977; Toch 2008; Toch and Kupers 2007). Thus, in these studies, punishment does not relate to the original penalty inflicted by the judge but, instead, refers to punishment aimed at controlling behavior or imposing revenge. Punishment inflicted for the purpose of controlling behavior can lead to a lack of trust, less exchange of information, and lower attained joint outcomes, which increases the likelihood of aggression (Fluttert 2010). Therefore, this "extra" punishment is ineffective, and can even be damaging in the long term (De Valk et al. 2015; Skinner 1972). The list of possible sanctions in residential settings is seemingly endless: meals of dry bread; no torn furniture replacement; bans on smoking, visits, or reading; cancelled leave; or withdrawal of points in the "token economy principle" (De Valk et al. 2015; Hanrath 2013). This last example works through soft power (Crewe 2009), which rewards discipline but punishes those who cannot regulate themselves, because they can never achieve these rewards.

Another characteristic of residential youth care institutions is that they are characterized by a certain amount of coercion. Exposure to coercive strains, arising from the "pains of imprisonment," negatively affects psychological wellbeing (Listwan et al. 2010, 2013) and increases suicides (Dye 2010; Listwan et al. 2013). The effectiveness of behavioral interventions deteriorates as the amount of coercion increases (Parhar et al. 2008); and, it is highly likely that coercion increases antisocial behavior and recidivism (Heynen et al. 2016; Pritikin 2009). Inmates may react to a lack of control by acting out against those whom they blame for restricting their freedom and personal control (Blevins et al. 2010; Colvin 1992); but, these inmates may also react in the same manner against peers, as a way of regaining some control and status (Harvey et al. 2006). An example of a coercive measure is solitary confinement (Pritikin 2009), sometimes in the form of segregated units in maximum or super-maximum (supermax) security prisons (Specter 2006), or a timeout in the inmate's own room (Sourander et al. 2002). The increased stress of this extreme isolation and confinement may impair inmates' mental health, which, in turn, may cause them to commit more violent acts (Haney2006). Furthermore, stress is known to produce cognitive impairment, dysregulate emotional responses, increase the likelihood of recidivism and relapse, and interfere with treatment benefits (Fishbein and Sheppard 2006). Conversely, the more 
personal control that youth feel they possess and can exercise within their settings, the less likely they are to experience adjustment problems (Blevins et al. 2010; Goodstein et al. 1984; Steiner et al. 2014).

As stated by Van der Helm et al. (2014), coercion in a secure residential context may be part of the structure that is necessary to set boundaries and prevent chaos and anarchy. This incorporates safety, a predictable day structure, and effective rule-keeping. Structure and safety in the living group are needed to stabilize youth's behavior and to enable effective treatment. However, the amount of coercion should always be balanced with flexibility (Van der Helm et al. 2009). If not, there is a danger that article 37 of the UNCRC (1992) might be violated:

States Parties shall ensure that [...] no child shall be deprived of his or her liberty unlawfully or arbitrarily. The arrest, detention or imprisonment of a child shall be in conformity with the law and shall be used only as a measure of last resort and for the shortest appropriate period of time.

Some provisions are specifically related to transgressions of professional behavior: the equality principle; child maltreatment; and, freedom of information, speech, and participation (UNCRC 1992). Souverein et al. (2013) assumed that coercion turns into repression due to an extreme power imbalance. Van der Helm et al. (2011) characterized repression by harsh and unfair control and punishment, a weak organizational structure, no flexibility, incremental rules, lack of privacy, extreme boredom, and humiliation of inmates. Heynen et al. (2016), however, proposed to separate deprivation (unsatisfactory living conditions, such as a lack of privacy and boredom) and repression, conceptually. In the Netherlands, the government and residential settings recognize these themes as relevant (De Lange et al. 2015; Inspectie Jeugdzorg and Inspectie voor de Gezondheidszorg 2015); and many settings are trying to create a policy that diminishes the nowcalled "repressive processes." After all, repression supposedly threatens the rehabilitative goal of a stay in a residential setting and may violate children's rights. However, research into the exact nature of repression is lacking, which makes it difficult for residential settings to know how to recognize and diminish repression, and also hampers empirical research on antecedents and consequences of repression in residential youth care.

\section{The Current Study}

The main research question of this article is as follows: "What is repression in residential youth care; and, which processes and circumstances may cause repression to occur?" To describe repression in residential youth care, literature from a humanistic perspective will be studied, as repression threatens human rights, humane relationships, and individual autonomy. Considering the processes and circumstances that cause repression to occur, social psychological, and organizational literature will be used to focus on aspects of repression that staff members, team leaders, and organizations can influence to a certain extent. To do so, this article reports the results of a scoping review. The discussion highlights how the results can be used in secure residential settings to detect, prevent or decrease repression.

\section{Method}

A scoping review was conducted to provide an overview of the nature and extent of available research literature about repression, and to disseminate research findings (Arksey and O'Malley 2005; Grant and Booth 2009). The scoping review identified the possible gaps in knowledge considering this topic. To achieve a comprehensive and in-depth review, different sources for research evidence were used: search of electronic databases; search through reference lists; manual search of key journals; and use of existing networks, relevant organizations, and conferences (Arksey and O'Malley 2005).

To find relevant literature for the (a) humanistic, (b) social psychological, and (c) organizational perspectives, search strings were created and used in relevant databases, which were, respectively, as follows: (a) Stanford Encyclopedia of Philosophy, with search terms "repression, liberty, autonomy, and psychiatry." To narrow these results, the philosophers "Foucault" and "Hannah Arendt" were added because first search results referred to these names; (b) Cumulative Index to Nursing and Allied Health Literature (CINAHL), Academic Search Premier, and PsycINFO, with search terms "repression, coercion, power, authority, empathy, attitudes, dehumanization, and morality"; and, (c) CINAHL, Academic Search Premier, and PsycINFO, with search terms "repression, coercion, seclusion, restraint, leadership, staff, and policy." The systematic database searches into social psychological and organizational literature were specified with "youth, children, or residential care/facility."

A first selection of literature was made based on title and abstract; and full texts of possible relevant literature were added to Mendeley Desktop. Subsequently, articles were included in the review if (a) the target group concerned a care group in a residential facility (not limited to youth care specifically, but included articles about forensic or justice settings and adult facilities, as well); (b) the article was oriented to Western cultures; (c) the article was in English or Dutch; and, (d) the article was published in a peer- 
reviewed journal. In the scoping review, it was possible to include all research designs and articles. Articles were excluded from the review if the article was written before the year 2000 (except for the philosophical literature), or if the evidence was not applicable to residential youth care. Literature was also manually searched to identify articles and book chapters that were missed in the database search. This was first performed by the snowball method, where certain articles were used as key documents and the citations of references to other sources about the same subject were followed to find other relevant documents. Second, articles and book chapters were searched based on attended conferences and literature suggestions of colleagues and experts. Again, the full texts of potentially relevant articles were added to Mendeley Desktop.

While reading the full text, it appeared that the distinction in perspectives in the literature lacked clarity. Therefore, some literature relevant to one perspective was also used for one of the other perspectives. In Fig. 1, the final results of the search strategy are systematically presented. Overall, 141 articles and book chapters were included in this review.

\section{Results}

Of the 141 articles and book chapters, 86 articles and book chapters concerned residential youth care institutions, or were applicable to these settings. The remaining 55 included articles and book chapters offered information about more general processes within the field of philosophy, sociology, and (industrial and organizational) psychology. Table 1 presents the overview of studies that considered youth or adult settings, whether the research was about residential or other settings, and what the goal of the studied settings was. There were 66 articles and books used in the humanistic perspective, 67 in the social psychological perspective, and 49 in the organizational perspective, with some articles or books used in two or three perspectives. Of the 141 included sources, there are 102 articles and 39 other sources, such as books, blogs, websites, and manuals. Of these 102 articles there are 82 articles published in peer-reviewed journals including 38 empirical articles and 44 theoretical articles. The 38 empirical articles include 12 qualitative studies, 21 quantitative, and 5 mixed method studies.

Fig. 1 Search and selection process

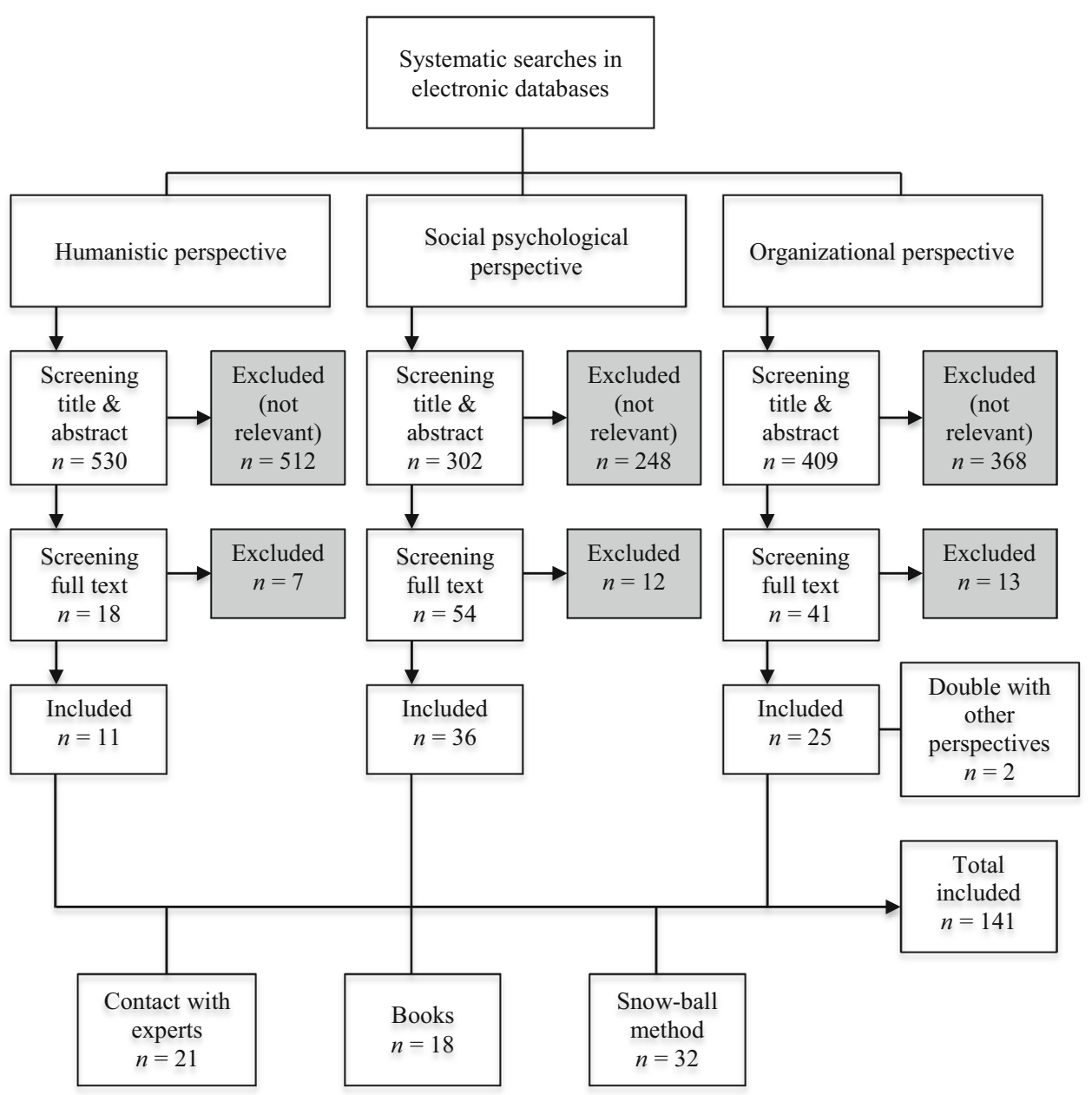


Table 1 Description of included studies considering or applicable to residential youth care

\begin{tabular}{lc}
\hline Variable & $n(\%)$ \\
\hline Total & $86(100)$ \\
Age & \\
Youth & $33(38.4)$ \\
Adult & $47(54.6)$ \\
Not specified & $6(7.0)$ \\
Setting & \\
Residential care & $70(81.4)$ \\
Other (e.g. school, medicine, parenting, outpatient) & $8(9.3)$ \\
Not specified & $8(9.3)$ \\
Goal setting & \\
Correctional institutions & $16(18.6)$ \\
Forensic psychiatry & $6(7.0)$ \\
Mental health care/psychiatry & $53(61.6)$ \\
Health care & $2(2.3)$ \\
Educational institutions & $4(4.6)$ \\
Not specified & $11(12.8)$ \\
\hline
\end{tabular}

\section{Humanistic Perspective}

\section{Repression Versus Freedom}

From a humanistic viewpoint, Shermer (2015) argued that all living organisms want to survive and flourish. To achieve this, an organism needs a certain amount of freedom and a minimum amount of repression. Repression literally refers to the act of using force to control a person or something (Merriam-Webster's online dictionary, n.d.). Antonyms for "to repress" are, among others, aid, allow, assist, encourage, free, empower, and let go. When controlling someone, that person's liberty, freedom, and autonomy are deprived, for there is an external person or agency that is controlling the person's behavior. Liberty and freedom can be distinguished from each other in that freedom is a state of being capable of making decisions without external control, while liberty is freedom that has been granted to people by external control (Waverly 2011). Usually, political and social philosophers use liberty and freedom interchangeably (Carter 2012). However, liberty and freedom are both needed to exercise autonomy.

\section{Repression Versus Autonomy}

In 1651, Hobbes argued in his seminal work on political theory, Leviathan, that when a conflict of interest arises, all organisms are sometimes acting at the consequence of others in order to survive and flourish. Thus, to protect society from self-motivated individuals, restriction of autonomy by the state was considered a necessary evil.
Two hundred years later, Mill (1859) stated that an individual should be autonomous, without interference of the government, as long as the individual does not harm others or others' autonomy. Mill suggested that, because society offers protection, people are obliged to behave in a certain way; and each member of society must defend and protect society and all its members from harm. Therefore, society must be given power to curtail behavior that harms others, but for no other reasons than that. Mill argued that the individual is the best judge of what he or she needs; and, the harm principle appeared to be the one and only justification Mill recognized for restricting liberty (Brink 2014). With this statement, Mill allowed no space for paternalism, which is the interference of a state or an individual with another person against his or her will, motivated by a claim that this person would be in more favorable circumstances, or protected from harm, by this interference. Consequently, some kind of deprivation of freedom or autonomy had to be involved (Dworkin 2014).

Sine (2008) argued that the limitation of youth's rights and autonomy, caused by the architectural design of residential facilities, was legitimate and ethical when used to prevent harm and danger. In modern society, children and youth with psychiatric problems, who pose a danger to themselves or others, are placed in residential settings from a paternalistic perspective. It is supposed to be in the best interest of the child, even though the child is usually not allowed an autonomous decision (Regan 2010; Shiffrin 2000). Due to the pre-emptive decision-making capacity of the youth's guardian or the legal system, the best interest of youth are sometimes more likely to be considered than the autonomy of the child (Kopelman 1997). Therefore, Regan (2010) stressed the importance of obtaining youth's consent, motivating them to develop problem awareness and intrinsic motivation, informing them on what to expect from treatment interventions, assessing their understanding of the situation, and, for example, using motivational interviewing (Miller and Rollnick 2002). Every child should be allowed the amount of freedom and autonomy that the youth can handle to promote learning and positive development (De Kogel and Nagtegaal 2008).

During admission to a residential setting, coercion is used, which is defined as the power to force compliance with authority using the threat of sanctions (Geller et al. 2006). This can be subtle (such as persuading the youth), or it can be quite overt (such as threatening with withdrawal of goods and privileges, or even deprivation of liberty, withdrawal of leave, or isolation), with force used to ensure compliance. Crewe (2009) described how this coercion was regulated by soft power in prison. Prisoners are encouraged to regulate their own behavior, putting the onus on them to govern their conduct, address their offending behavior, engage positively with the regime, and accept 
responsibility for any failings to do so. Crewe stated that these policies provide prisoners with pseudo-autonomous space in which to make decisions about their lives, while at the same time training them to exercise this autonomy in particular ways, and rewarding them for doing so. Where prisoners fail to regulate themselves appropriately, the prison's authoritarian face reveals itself through the orders, controls, and punishments that prisoners have no latitude to negotiate.

\section{Humanizing Punishment and Control}

In the Middle Ages, punishment was mostly cruel and harmful (Pinker 2011). Prison reform in England (John Howard) and in the US (Joshua Jebb) was founded on the idea that separating an offender in a cell with a Bibleapart from bad influences-would lead to redemption. In his book Discipline and Punish: The Birth of Prison, Foucault (1977) described the development of this "gentler," modern way of imprisoning criminals rather than the forced labor, torture, or death that occurred before the $18^{\text {th }}$ century (Gutting 2014). Although the consequences to the prisoner's body were less severe due to the new system, the reform became a vehicle of more effective control. In this way, the prisoner's body was replaced by the prisoner's soul as a key element in the penal system. Foucault (1977) addressed the relationship between freedom and modern residential institutions by describing the "Panopticon" idea as a means of total control. From the middle observation post of a round prison, guards always had eyes on every prisoner, hence, Panopticon, which means "seeing everywhere" in ancient Greek. Foucault's analysis showed how techniques and institutions, developed for different and often quite innocuous purposes, converged to create the modern system of disciplinary power (Gutting 2014).

Three techniques of control are central in Foucault's disciplinary society: hierarchical observation, normalizing judgment, and examination. Hierarchical observation refers to a person with more power (staff) observing people with less power (youth). The principle of normalizing judgment is applied to correct deviant behavior. The goal of this correction is not revenge (as in the case of the tortures of premodern punishment), but reform; the youth should come to live by society's standards and norms. The examination is a method of control that combines hierarchical observation with normalizing judgment. It elicits the truth about those who undergo the examination (the youth) and controls their behavior by directing them, for example, to a course of treatment. Foucault argued that disciplinary power is most effective when hierarchical observation, and the knowledge it produces, is combined with normalizing judgment and examination. In other words, discipline functions best when the information obtained by means of surveillance is incorporated into a system of micro-penalties-a system in which ranking serves as punishment or reward (Foucault 1977; Jacob and Foth 2013).

Normalizing judgment in residential youth care often takes the form of a reward or privilege system implemented by staff who must reinforce corrective strategies (micropenalties) and, during the process, encourage the adoption of prescribed conducts, habits, and attitudes imposed by the staff (Du Plessis 2013; Jacob and Foth 2013). In modern youth care, this reward system is widely used (sometimes called "the competence model"), but it is not without criticism (Holmes and Murray 2011; Stams and Van der Helm 2016).

Foucault cultivated a deep suspicion toward the claims that contemporary society had significantly humanized the forms of punishment by abandoning the savage corporal brutality that prevailed in the old days in favor of the hidden concrete-and-steel carceral system of the modern area (Bedau and Kelly 2015; Du Plessis 2013). His suspicion was aroused by the question of who decides what is normal and what is deviant behavior? Which rules and laws are youth or prisoners supposed to follow, and who decides upon the consequences if the imprisoned choose not to obey? Historically, in psychiatric hospitals or asylums, the doctor was the authority with all the power (Goffman 1961). The relationship between doctor and patients was characterized by binary opposites. The doctor was active, authoritative, sane, and moral, whereas the patients were passive, powerless, insane, and immoral. In addition, they lacked the means to care for themselves. As such, power and clear in- and out-groups underpinned this relation (Bandura 1999; Du Plessis 2013; Paterson 2011).

In modern residential youth institutions, the relationship between staff and youth is still grossly unequal in terms of social power (Chow and Priebe 2013; Crewe 2009; Paterson and Duxbury 2007). Staff is able to dictate and impose restrictions on the movements and activities of the youth (Laing 1974); and, the youth lose autonomy, self-determination, and independence (Du Plessis 2013). Power differences can cause dehumanization of youth (Lammers and Stapel 2011), and the needs to take youth into consideration diminishes, which in turn increases the likelihood of imposed restrictions and punishment (Haque and Waytz 2012; Lammers and Stapel 2011; Paterson and Duxbury 2007; Paterson 2011; Zimbardo 2007). The combination of power and dehumanized youth greatly reinforces the level of punitiveness by staff (Bandura 2002; Shermer 2015).

The normalizing judgment seems to be subject to the context of time and place. How this concept of "normal" can take severe and extreme forms becomes painfully clear in totalitarian regimes. During the Nazi regime, being a Jew was "deviant" from the standard and, as a 
consequence, much of the Jewish population was deported to concentration and extermination camps. In Eichmann in Jerusalem: A report on the banality of evil, Arendt (1963) turns her attention to individual culpability for evil through her analysis of the Nazi functionary Adolf Eichmann who was tried in Jerusalem for organizing the deportation and transportation of Jews to the Nazi concentration and extermination camps. Eichmann's main defense appeared to be that he was just following orders. This is sometimes echoed in secure youth care where "following orders" is replaced by "following procedures," often to hide professional uncertainty and fear (Van der Helm et al. 2006) without reflection on the needs and rights of the youth (Höfte et al. 2012).

\section{Evil or Wrongful?}

The concept of evil may be bit of an overstatement when referring to repression in residential youth care settings. Evil is characterized by the most despicable sorts of actions, characters, and events (Calder 2014). Because it involves moral condemnation, only moral agents (i.e. humans) can act or be evil. According to Steiner (2002), the extra quality shared by all evil actions, which is lacking from merely wrongful actions, is the perpetrator's pleasure. Evil action consists of taking pleasure in doing wrong, or some ideological drive to harm others (Baumeister and Campbell 1999; Pinker 2011; Shermer 2015), although there might exist a huge gap between the victim's and the perpetrator's perceptions of the act (Baumeister and Campbell 1999). Furthermore, Calder (2014) argued that it is an essential property of evil actions that the evildoer intends for the victim to suffer significant harm, while it is not an essential property of wrongful actions that the wrongdoer intends to cause harm.

There are occasions in residential youth care settings that staff is acting in a wrongful manner, without taking pleasure from it or without the intention to harm. For example, placing a child in isolation in the child's room when refusing to go to school violates children's rights. According to Foucault's normalizing judgment, not going to school is considered abnormal by staff, and if the child shows deviant behavior by not going to school, the consequence is that the child is not allowed to leave the child's room. However, when taking the Dutch law as an example, this deprivation of liberty is only allowed if there is a danger for the youth or for others, and if there are no less intrusive options available to manage the situation (Law Special Admissions in Psychiatric Hospitals 1992. In Dutch: Wet Bijzondere Opnemingen in Psychiatrische Ziekenhuizen, BOPZ). This law is based on the European Convention on Human Rights (ECHR 1953), which allows liberty to be deprived on grounds of "unsound mind."

\section{Coercion}

In many countries, laws have been developed-like the Dutch law (BOPZ) - that allow for involuntary, non-consensual, and forced treatment in mental health care: coercive measures can be used in cases of crisis. Coercion is the power of an authority figure to force compliance using the threat of sanctions (Snow and Austin 2009) and it is often used as related to episodes where youth are either threatening, aggressive, or self-harming, and where verbal interventions are, according to staff, insufficient to control the situation (Gelkopf et al. 2009; Wynn2003; Wynn et al. 2011).

In residential youth care, coercive measures can take the form of solitary confinement, separation, fixation, or forced intake of medication or food and fluids. Furthermore, the liberties of youth in residential settings may be restricted in making phone calls, sending and receiving mail, receiving visitors, and moving freely within or outside the building. In practice, the judgment of the necessity of restricting the liberty is at the discretion of the individual direct-care staff and is highly subjective (Huckshorn et al. 2014). Because of the possible negative and harming effects of coercion, many researchers and organizations have concluded that the use of coercion should be minimized, and only be used as a last resort when immediate harm is likely, or should be eliminated completely (American Psychiatric Nurses Association 2001; Brendtro and Mitchell 2012; LeBel et al. 2010; Paterson and Duxbury 2007; Regan2010; Romijn and Frederiks 2012; Stams and Van der Helm 2016; Van Doeselaar et al. 2008). Conversely, there are proponents of coercive measures who argue that, in the face of limited alternatives, it is necessary to protect staff and other youth on the ward from aggressive behavior (Davidson et al. 2005; Day et al. 2010).

In the field of psychiatric care, there is an ongoing ethical and professional debate as to whether coercion should be allowed (Day et al. 2010; Delaney 2001; Elling Ellingsen et al. 2011; Gelkopf et al. 2009; Paterson and Duxbury 2007; Prinsen and Van Delden 2009; Taxis 2002; Wynn et al. 2011). If so, in which situations should coercion be considered acceptable, and which particular types of coercion are safe and effective? This debate is also relevant for the field of residential youth settings, because restraint and seclusion continue to be used on youth in residential settings at higher rates than on adults in care (Bowers et al. 2014; LeBel et al. 2010). Researchers have found that restraint is used on $30 \%$ of youth in juvenile facilities, schools, and residential treatment programs (Kennedy and Mohr 2001), and that noncompliance is often the starting point of coercive cycles (Smith and Bowman 2009).

Important issues in this debate are the youth's autonomy, human dignity, possible negative consequences (e.g. 
stress, fear, detriment to the treatment process, increase of aggression), and lack of evidence for positive effects of coercion (Caldwell and Lebel 2010; Gelkopf et al. 2009; Gilburt et al. 2010; Prinsen and Van Delden 2009; Regan 2010; Wynn et al. 2011). Furthermore, the use of coercion may weaken the therapeutic alliance between staff and youth (Prinsen and Van Delden 2009; Roest et al. 2016; Steckley and Kendrick 2008). Some researchers even posit that coercion is used primarily for staff convenience, and that there is no therapeutic effect (Busch and Shore 2000; Paterson 2011). Physical restraint has even been a frequent feature of practices referred to as holding therapy (Mercer 2013) or supermax prisons (Haney 2006; Rhodes 2007).

\section{Conclusions Humanistic Perspective}

Although the law (especially in reference to article 37 of the UNCRC) is supposed to protect the rights of youth who are admitted to residential institutions, it leaves opportunity for arbitrary application of the law and lack of professional behavior. For example, who is to decide when a youth poses a danger to self or others, what restraining measures are acceptable, and how should staff handle infractions of rules? And, who is to judge if no less intrusive options are available? The normalizing judgment depends on person, place, and time. Based on the humanitarian approach, repression can thus be characterized by an authority figure intentionally acting in a way that harms the youth, or unlawfully or arbitrarily depriving the youth of liberty or autonomy.

\section{Social Psychological Perspective}

\section{Transactional Processes and Repression}

Hannah Arendt's claim that evil is banal was supported by the Stanford Prison Experiment (Haney et al. 1973), showing that brutality was a "natural" consequence of being in the uniform of a guard and of asserting the power inherent in that role, even in the absence of an obviously malevolent authority. Haslam and Reicher (2012), however, showed that conforming to the role of the guard was not enough to evoke the dominant and inhumane behavior of all of the guards.

Van der Helm and Stams (2012) indicated in their research that the transactional processes of youth prisons (Hastings 2005; Lee 2013; Polvere 2014; Sameroff 2009) can slide into coercive cycles where youth's negative behavior evokes unprofessional behavior by staff, which in turn, causes again negative behavior by youth (Petti et al. 2001; Smith and Bowman 2009). Other research also described how a "treadmill of violence" could be the outcome when staff tries to handle unwanted behavior of persons with intellectual disabilities with coercion because they feel powerless (Strand et al. 2004). When staff is unable to maintain control over the youth, or when their authority is threatened, they become fixated on controlling the youth (Modlin 2015). In these situations, violence and bullying against youth have even been found to occur (Hutchinson et al. 2013). Furthermore, staff's attitudes and cognitive distortions toward youth also influence staff's behavior. For example, if staff members believe that "bad behavior" of youth is controllable, and originates from poor character or coping skills, staff is more likely to treat youth with disrespect, or to subject them to neglect, passive treatment, or even open hostility (Hastings 2005; Koekkoek et al. 2011; Lambrechts et al. 2009; Lee 2013; Modlin 2015; Petti et al. 2001; Stone 2001). Staff may feel obstructed, frustrated, and willfully denied in their competency, which easily leads to rejection of the particular youth, or plain resentment and dehumanization (Koekkoek et al. 2011). The likelihood of these transactional processes leading to repression is fueled by intrapersonal processes (fear, empathy, dehumanization, and rationalization), which are mediated by interpersonal processes (socialization within a team and identification of staff members with team leader). In this way, transactional processes are active between dispositional and situational factors (Mohr and Horton-Deutsch 2001; Sameroff 2009).

\section{Intrapersonal Processes}

Fear In residential settings, staff members need to interpret the behavior of youth from two perspectives: (a) the wellbeing of the youth and (b) the possibility of threatening actions which endangers staff's personal safety (Jacob et al. 2008). The combination of these two perspectives often leads to ambiguity as to how to interpret social or behavioral cues from youth (Hanrath 2013). Fear can rise from a continuous threat of aggressive behavior of the youth (Jacob et al. 2008), possibly leading to a hostility bias with respect to interpreting these cues (Hanrath 2013). Consequently, staff may interpret all youth's behavior as a sign of imminent threat and, therefore, deploy controlling measures in order to ensure safety (Jacob et al. 2008; Saloviita 2002; Stone 2001; Van der Helm and Stams 2012). When staff experiences no threat, a more tentative and exploratory approach is adopted (e.g. asking questions first before taking defensive actions; Navarick 2013).

Repeated exposure to aggression and violence, including involvement in coercive measures, can cause a range of symptoms in staff, including emotional numbing, burn-out, hyperarousal, and hypervigilance (Hastings 2005; Lambert et al. 2015; Paterson 2011). Enduring stress can cause a decrease in the hypothalamus-pituitary-adrenal (HPA) axis (Popma and Raine 2006), resulting in reduced fear 
conditioning, greed, and antisocial behavior (Raine 2013). If fear, anger, and frustration are not acknowledged, they can obstruct therapeutic relationships with youth (Paterson 2011). Countertransference, evoked by exposure to aggression and violence from youth, diminishes empathy by staff, causing a cycle of reactance, retaliation, and revenge (Paterson and Duxbury 2007; Stone 2001).

Empathy A lack of empathy is related to repressive behavior, such as harsh punishments (Keysers 2011). Empathy is unlikely when engagement is shallow, instrumental, or tainted by mutual suspicion (Crewe 2009). On the contrary, the presence of empathy has been associated with successful therapeutic relationships, more altruistic behavior, less aggression, and higher scores on measures of moral judgments (Marr and Ezeife 2006).

Empathy seems to be hardwired in the human brain (De Waal 2010) in order to enhance cooperation and survive as a collective in hunter-gatherer times (Damasio 1994; Boehm 2012; Mussweiler and Ockenfels 2013). Evidence for the biological basis of moral emotions, such as empathy, comes from research with 1-year-old babies who show an inborn moral sense in experiments (Bloom 2013). Moral emotions are facilitated by brain hormones like oxytocin and serotonin (Den Ouden et al. 2013) and can be particularly important in times of stress because of their "steering preference" (Frijda 2007). On a societal level, the collective had to be defended against free riders and bullies (Boehm 2012), which meant that humans also needed to be able to punish free riders in order to warn others (Kurzban et al. 2006). According to Keysers (2011), the male brain has especially evolved this faculty for cooperation together with dominance and aggression, in order to be able to reproduce and survive, as well as apply revenge and moralistic punishment. This capacity is facilitated by brain hormones like testosterone and dopamine, which can counteract oxytocin and serotonin, and thereby down regulate empathy (Den Ouden et al. 2013; Keysers 2011), epigenetically regulated by environmental stress (Rodgers et al. 2015). The males even activated a region of the brain that is involved in processing reward; they literally appeared to enjoy seeing the "bad guy" punished (Keysers 2011; Singer et al. 2006). This translates into male staff being more prone to choose highly restrictive interventions and to show greater approval of coercive interventions than female staff (Gelkopf et al. 2009; Wynn et al. 2011).

Some researchers oppose the conclusion of the inevitability of dominance and aggression (Russett and Oneil 2001; Baron-Cohen 2003; De Waal 2010; Pinker 2011; Shermer 2015). They state that trade, education, the state's monopoly on violence, and international transparency diminish the tendency for repression in our society in favor of more cooperation and empathy. Still, Shermer
(2015) warns of giving one person too much power, which can lead to excesses. He calls this the "Hobbesian trap": competition can lead to instrumental violence, fear-inspired repression; honor and ideology can lead to dehumanization (Kteily et al. 2015). Empathy is often proposed as a requirement for overcoming dehumanization (Baron-Cohen 2003; Halpern and Weinstein 2004; Haslam 2006), because active engagement with another person's inner thoughts and feelings requires attributing humanity to that person.

Dehumanization and Repression Dehumanization involves stripping experience (the capacity to feel pleasure and pain) or agency (the capacity to plan, intend, and exert choice) from youth (Haque and Waytz 2012; Haslam 2006), allowing staff to experience less moral concern about their actions toward dehumanized youth, and justify acts that would otherwise be considered harmful (Bandura 2002; Haque and Waytz 2012; Paterson 2011). However, it has been found that certain forms of dehumanization are functional (Haque and Waytz 2012), because they enable staff to cope with the stressful demands of interacting with troubled youth (Haque and Waytz 2012; Vaes and Muratore 2013).

It is assumed that dehumanization is more likely to arise when there is little contact between people or groups (Viki et al. 2012). Social practices that divide people into ingroup and out-group members produce human estrangement, which fosters dehumanization (Bandura 2002). That is why staff in residential settings may attribute fewer human traits, rights, emotions, and experiences to youth, the out-group, than oneself, the in-group (Bandura 1999; Kteily et al. 2015; Mohr and Horton-Deutsch 2001; Paterson and Duxbury 2007). The youth's emotional experiences and perspectives are viewed as illegitimate; their identities become increasingly defined by their deficits; and, they are positioned as inferior and incompetent (Apter 2003; Du Plessis 2013; Paterson and Duxbury 2007; Polvere 2014). This increases the likelihood of less staff attention and social exclusion. Consequently, the likelihood of staff's support for rehabilitation decreases (Haque and Waytz 2012; Viki et al. 2012). Furthermore, when staff find it hard to witness progress in the treatment of a particular youth, their work may feel insignificant and meaningless. In such cases, there is a danger of reducing the youth to an object from which staff can distance themselves, allowing staff to focus on completing a task, rather than on evaluating observable changes with the youth and understanding the global effects of their care (Jacob and Foth 2013).

Humanization, because of empathy, has the power to counteract repressive acting (Bandura 2002). Within the sample of correctional staff, Viki et al. (2012) found that good quality contact is related to increases in perceived 
humanity and this, in turn, is related to more support for rehabilitation. Professionals who are physically and emotionally close to youth are more likely to understand them as a unique person needing individual care (Larsen and Terkelsen 2013). To avoid dehumanizing attitudes toward youth, staff should attribute mental states to them, viewing them as distinct individuals with unique qualities, and perceiving them as engaging in reciprocal behavior (Bandura 2002; Haslam 2006). A milder form of dehumanization is rationalization.

Rationalization and repression Rationalization, in general, is known as a cognitive defense mechanism that helps individuals to distance themselves, and their group, from the aberrant moral stance implied by their actions (Ashforth and Anand 2003). It offers not only an excuse for their acting, but it also encourages staff to forget such acting, or to reframe it as something necessary-perhaps even desirable (Ashforth and Anand 2003; Larsen and Terkelsen 2013; Saloviita 2002). In this justification process, detrimental conduct is made personally and socially acceptable by portraying it as socially worthy, or as serving moral purposes (Bandura 1999).

Rationalization can take the form of euphemistic labeling or passive talking; harmful conduct is then made respectable by camouflaging it in innocent or sanitizing language (Bandura 2002). For instance, Holmes and Murray (2011) showed how, in a correctional facility, punishment is portrayed and rationalized as therapy. The concept of a "timeout room" is one typical example. Although it sounds therapeutic, timeout rooms are ostensibly used to extinguish bad behavior through seclusion and restraint (Petti et al. 2001; Du Plessis 2013). Rationalization also closely links to habituation; the more often professionals use seclusion, the more positive they are about its use (Gelkopf et al. 2009; Van Doeselaar et al. 2008; Wynn et al. 2011). Habituation to restraint and seclusion brings with it acknowledgement of the necessity and desirability of its use, and it becomes a legitimate and justifiable practice. This could be explained by the choice-supportive bias, such as cognitive dissonance (Festinger 1957). It is not only staff who do not have direct contact with restraint and seclusion, such as managers, psychologists and social workers, but also staff who work on an open ward, who generally hold negative attitudes toward coercion (Gelkopf et al. 2009; Van Doeselaar et al. 2008; Wynn 2003). They might be more able to distance themselves from departmental culture, which enables them to think of possible alternatives to coercion (Van Doeselaar et al. 2008).

\section{Interpersonal Processes}

Whether or not the intrapersonal processes lead to repressive behavior by an individual staff member is dependent on two main social processes: identification with the formal or informal team leader and socialization within a team. A formal or informal team leader influences staff behavior because staff members may identify themselves with the team leader. When this team leader is highly repressive, staff members are likely to behave repressively as well. The process of socialization means that newcomers are subjected to the values, beliefs and norms of a team (Ashforth and Anand 2003; Paterson 2011). The effect of dehumanization and rationalization becomes more potent when shared with team members (Ashforth and Anand 2003).

Identification and repression Australian researchers (Hutchinson et al. 2013) presented a case representing repression through identification. In this case, bullying and coercive behaviors by nurses caused a moral vacuum of wrongdoing that ruined nursing care, replacing it with punishment and mistreatment. One particular patient, after a suicide attempt, was tormented by being denied sleep ("We'll do his observations every hour ... just to annoy him."), and by undermining his claim to illness publicly and repeatedly ("He attempted suicide purely for attention."). Under the influence of a nurse who operated as a "ringleader," others on the team violated their own ethical standards and became functionaries of corrupted care processes also.

Although Milgram (1963) stated that, ultimately, most people follow orders of authority despite the immoral consequences, immoral behavior is more likely to occur if there is a high level of identification with the formal or informal leader or system that stimulates repression (Haslam and Reicher 2012). The more charismatic the leader, the greater the identification, trust, and reflexive obedience that leader is likely to engender among subordinates (Ashforth and Anand 2003). Recent research (Steffens et al. 2015) adds to this conclusion that, besides charisma, the team leader should be viewed as one of the group. In this way, identification with a repressive leader increases the likelihood of repressive behavior of staff members; but, identification with a leader who empowers staff members and stimulates shared decision-making (transformational leadership) is related to less coercive behavior of staff (Delaney 2001; Van der Helm et al. 2006). In general, being a subordinate may induce persons to abdicate responsibility for moral issues (Ashforth and Anand 2003; Larsen and Terkelsen 2013; Navarick 2013). When staff experience moral ambivalence (i.e. the sense that one could judge the same action as either right or wrong, and have a feeling of discomfort over the conflict), it is more likely that they allow their leader to direct their actions, shifting the responsibility to the person giving orders (Navarick 2013). 
When recurrent immoral behavior by staff members is tolerated by authority figures, it is known that wrongdoing can create permissive climates that foster unethical conduct by staff members (Ashforth and Anand 2003; Hutchinson et al. 2013). Staff can convince themselves that the wrongdoing is legitimate, and that authorization by those in power nullifies the necessity of the actors to make their own judgments or choices (Mohr and Horton-Deutsch 2001). In this way, absent or passive leadership can also foster repressive behavior as a shared ideology.

Socialization and repression Staff also influences each other within their team; they develop shared ideologies by using one another as reference points. Hastings (2005) suggested that informal cultural variables are the most powerful social influence because teams spend a majority of their time together with minimal supervision from managers. Team members turn to each other for support and confirmation of the meanings that they ascribe to events around them, and for approval and disapproval of patterns of behavior (Ashforth and Anand 2003; Larsen and Terkelsen 2013).

Staff more readily accept guidelines for conduct when they emerge from within the group, rather than when such guidelines are imposed externally (Haslam 2014; Mohr and Horton-Deutsch 2001). This explains why a team culture influences staff's behavior more strongly than education and training (Delaney 2001). Furthermore, when there is a high sense of belonging to the team (caused by, among other things, high within-group task interdependence, peer-based socialization, and physical proximity; Trice and Beyer 1993), an individual staff member may bend one's own general commitment to ethics under pressure of social circumstances (Ashforth and Anand 2003). In a team that is cohesive, which consists of homogeneous members functioning in relative isolation from dissenting viewpoints, and has a directive (sometimes informal) leader who signals what decision is favored, groupthink is likely to occur (Janis and Mann 1977). This involves a group suppressing dissent in the interest of group harmony. When a new team member arrives and faces a strong, repressive culture, it is likely that the new member adopts the repressive ideologies to integrate and, eventually, internalizes and owns the ideologies.

\section{Conclusions Social Psychological Perspective}

The social psychological perspective provides explanations for repression. The social context consists of a formal (team leader) or an informal ("ringleader") leader, the staff, and the youth who influence each other (transactional processes). Whether these transactional processes lead to repressive behavior by staff depends on several individual staff processes (intrapersonal), but, in addition, the interaction between team members and their team leader (interpersonal) also influences them. On the intrapersonal level, fear, lack of empathy, dehumanization, and rationalization increase repressive behavior. On the interpersonal level, leadership is related to repressive behavior by staff in two ways: (a) a lack of leadership may create a permissive ethical climate that fosters repressive behavior by staff, or (b) a leader may stimulate repressive behavior of staff members who highly identify with this leader. Furthermore, team members influence each other through socialization. When there is a high sense of belonging to the team, an individual staff member may bend one's own general commitment to ethics under pressure of social circumstances.

When these insights are combined with the definition based on the humanistic perspective, the following can now be stated: Repression is a transactional process between youth and authority figures, characterized by an authority figure intentionally acting in a way that harms the youth, or by an authority figure unlawfully or arbitrarily depriving the youth of liberty or autonomy - enabled by intrapersonal processes in authority figures (fear, rationalization, lack of empathy, dehumanization) and mediated by interpersonal processes (socialization and identification).

\section{Organizational Perspective}

Still absent from the description of repression is how it is influenced by a broader context: the organization of residential institutions. An essential aspect of residential institutions is a physical environment that limits departure from the facility and social interaction with the outside environment (Goffman 1961). Since the early nineteenth century, the architectural layout of asylums (now, secure residential settings) originated from a belief that a cure could not occur unless psychiatric patients were isolated from their familiar home environment and put into a suitable "therapeutic space" (Chow and Priebe 2013). Confinement was the method by which society could control and exclude the deviants (Foucault 1977; Jacob et al. 2008). As soon as youth enter this environment, very often with locked doors, high walls, and barbed wire, they are subjected to policies and legal frameworks regulating care. From the organizational literature, it appears that the organization influences the amount of repression at three levels: (a) the approach and structure of the organization, (b) the person-environment fit (P-E fit), and (c) the staff selection. Institutionalization of repressive routines explains how repressive behavior becomes embedded in the organizational culture and, consequently, makes it difficult to counter.

\section{Organizational Approach}

Some institutions have more repressive policies than others due to differences in approach to institutionalized youth. In 
the literature, several approaches and models are described but, in general, the tension between an orientation toward correction and control, and an orientation toward treatment and rehabilitation is apparent (Lipsey 2009). The American juvenile justice system was originally characterized by a correctional approach based upon a quasi-military model of discipline, drill, and ceremony (MacKenzie 1997). As in the adult penal system, the underlying goal of correctional programs is punishment, as these programs rely on systems of harsh penalties and deprived environment to correct offenders' attitudes and behaviors. Correctional programs conform to the control model (Dilulio 1987), wherein administrators believe that inflexible, strict controls should permeate all aspects of prison life. Both inmates and staff are then subjected to certain controls due to a presence of hierarchy. Another model that is routinely used to describe youth institutions is the medical model (Adame and Leitner 2008). This model positions youth as self-contained and passive objects, and holds the idea that the source of clinical symptoms and behavior problems are located within the youth themselves.

Alternatively, there are proponents of rehabilitation and recovery in residential institutions-for example, institutions that use the "sociotherapeutic model" (Schaftenaar 2015). To work on rehabilitation and recovery, social cohesion is a necessary precondition, which at the same time leads to an orderly prison (Craig 2004). In contrast to the medical model, Polvere (2014) stated that transactional processes influence the treatment outcome, and therefore, a recovery-oriented model is necessary. This model positions the youth as a capable and active agent, which disrupts the traditional power imbalance that extends from the medical model. Researchers (Craig 2004; Lipsey 2009) point out the possibility that security and rehabilitation might, in fact, be feasible, if more permissive and therapeutic organizational models were used. Therefore, many institutions strive to adopt an approach that is more oriented toward therapy and rehabilitation (Abrams et al. 2005; Jolivette and Nelson 2010; Nelson et al. 2010). These approaches promote balanced, collaborative partnerships between practitioners and service users, build upon strengths, and encourage decision-making and self-management (Dilulio 1987; Ridgway 2001). Other studies have agreed that a punitive environment and less structured or enriched activity periods are associated with an increased use of seclusion and restraint and aggression in children (Busch and Shore 2000; Miller et al. 2006; Huckshorn et al. 2014).

Also, approaches that are oriented toward rehabilitation (because of their focus on increasing "good behavior") can be overly controlling and repressive, particularly when not used correctly. For example, in many programs, conversations and interventions are superficial and focus almost exclusively on the concrete events of daily living and the cooperation of the youth (Modlin 2011). Furthermore, rigid behavioral (modification) programming and point-systems continue to abound, while it has been shown that these programs are largely dependent on a particular staff member's reaction in a given instance, and that there is little room for individual treatment and autonomy (Miller et al. 2006; Holmes and Murray 2011; Modlin 2011).

\section{Organizational Structure}

Social dominance theorists make a distinction between two types of institutions: hierarchy-enhancing (HE) institutions and hierarchy-attenuating (HA) institutions (Haley and Sidanius 2005). The HE institutions can be identified as those most likely to promote hierarchically structured relationships among social groups. HA institutions, on the other hand, defend subordinate social groups and generally facilitate both an egalitarian distribution of positive social value and the subsequent attenuation of group-based social hierarchy. One institution may contain differently oriented departments (HE and HA) — for example, prison guards (HE) and social workers (HA) within the criminal justice system. A clear hierarchy originally characterized residential institutions (Craig 2004; Dilulio 1987; Ibsen 2013; Paterson 2011; Paterson and Duxbury 2007). Hierarchy is connected to power and, as shown, power enhances the likelihood of repression and dehumanization by authority figures (Kteily et al. 2015). Hierarchical organizations often attract staff who strongly believe in social hierarchy (Kteily et al. 2015), which can be explained by the P-E fit.

\section{Person-Environment Fit}

The organizational approach and the institutional structure can, either promote repressive or rehabilitative behavior by staff at the same time. Recently, many residential institutions adopted a more therapeutic orientation. However, as several researchers have demonstrated (Abrams et al. 2005; Craig 2004; Du Plessis 2013; Quirk et al. 2006; Van der Helm et al. 2006), institutions are struggling to find a balance between a correction and a treatment approach. This challenge may be explained by incongruence in approach and structure of the institution and the staff's attitudes (Lambert et al. 2011). Staff may still be punishment or control-oriented, although the organizational approach and structure do not promote this (Nelson et al. 2010; Smart 2012). In this way, a misfit between person and environment occurs according to $\mathrm{P}-\mathrm{E}$ fit theory (Edwards et al. 2006). The P-E fit theory explains how the environment influences staff's actions. For example, within highly formalized institutions, staff members behave more paternalistically toward youth; but in less formal ward environments, staff members are more in agreement with 
youth (Quirk et al. 2006). Also, Lambert et al. (2011) found that support for punishment was greatest among correctional officers and lowest among those who occupied positions aimed at providing treatment interventions (counselors, case managers, teachers, etc.).

The P-E fit is driven by five non-mutually exclusive processes (Haley and Sidanius 2005): self-selection (individuals choose a work environment that matches their attitudes), institutional selection (institutions hire staff who hold the right attitudes), institutional socialization (staff's attitudes are shaped by forces such as institutional rules, incentives, and peer pressures), differential rewards (staff with congruent socio-political attitudes receive rewards, such as positive performance ratings and high salaries), and differential attrition rates (staff tends to leave the institution when there is a lack of congruence). Due to these processes, a repressive team typically consists of a highly homogeneous group of people with the same attitudes (Ashforth and Anand 2003). According to P-E theory, people who endorse societal hierarchies tend to be found in institutional settings that function to build and maintain group-based social hierarchies; and people who endorse egalitarianism tend to be found in environments that function to attenuate hierarchies.

However, staff may also find a way to avoid incongruence between their attitudes and the organizational approach and structure (Ibsen 2013; Paterson and Duxbury 2007). Ibsen (2013) showed that staff of a Norwegian prison created their own informal reward system, so they would not have to obey to the limits set by prison management. Due to this reward system, privileges are given regularly so they can be withdrawn when staff wants to punish a prisoner. Because these privileges are not registered, there is no need to register the punishment either. Ibsen (2013) stated that such a system is possible due to a lack of communication between management and staff.

\section{Staff Selection}

The P-E fit theory states that organizations can also influence the amount of repression by hiring the "right" staff. The more educated staff members are less likely to favor restraint and seclusion (Wynn et al. 2011; Lambert et al. 2015), because they possess stronger negative attitudes about such techniques (Busch and Shore 2000; Regan 2010; Suen et al. 2006). The least experienced staff members are more often involved in managing restraint situations and, thus, are more likely to suffer injury (LeBel et al. 2010). Unskilled staff are the most restrictive in the case of self-harming situations (Wynn et al. 2011). Less qualified staff also consider annoying behavior of patients to be an adequate reason for restraint (Gelkopf et al. 2009). It has been suggested (Bowers et al. 2014; Gelkopf et al.
2009; Nelson et al. 2010) that these results may stem from a lack of tools for coping with annoying actions and insufficient knowledge of psychopathology, which could explain the patients' annoying behavior. Researchers (Van der Helm et al. 2006) also pointed to fear of losing control and lack of leadership, which can lead to a loss of patience and an inability to cope with the situation without physical restraints. This explains why some consider the use of restraint on children to be a "treatment failure" (Smith and Bowman 2009). However, most staff members are also trained and equipped to identify potential problem situations and swiftly move to control these perceived situations with coercive measures (Nelson et al. 2010) instead of reacting with de-escalation techniques (Van der Helm and Schaftenaar 2014). This likely results in increased rates of restraint after training (Delaney 2001; Paterson and Duxbury 2007).

Furthermore, the staff-youth ratio influences the variability in use of restraint and seclusion; when there is not sufficient staff present, the amount of coercive measures increases (Gelkopf et al. 2009). The presence of men on the ward has been shown to reduce the need for restraints (Gelkopf et al. 2009), although results have been proven inconsistent (Busch and Shore 2000; Wynn 2004).

\section{Institutionalization: Repressive Routines in Organizational Culture}

At all three organizational levels, repressive routines can be institutionalized. Ashforth and Anand (2003) created a model to explain how corruption becomes normalized. In other words, how corruption (i.e. repression) becomes embedded in the organizational culture and internalized by staff members as permissible, and even desirable, behavior. This corruption is subsequently passed on to successive generations of members (Schein 2004). The term corruption may seem strange at a first glance, but if defined as the misuse of authority for personal, subunit, or organizational gain (Ashforth and Anand 2003), it is useful in the understanding of repression. Also, Paterson (2011) used the term corruption to describe abuse of coercive measures in facilities for learning disabled patients. The model is based on three pillars, which are mutually reinforcing in normalizing repression: institutionalization, rationalization, and socialization. While the latter two were addressed in the section on social psychological factors, institutionalization refers to the process by which repressive practices are enacted as a matter of routine (following procedures), often without conscious thought or reflection about their propriety.

Institutionalization of repression can be linked to a nonreflective team (Heneghan et al. 2014) and a permissive ethical climate, at the societal and organizational levels, 
which are closely connected to the behavior of the team leader. Authorizing repression can take the form of informal encouragement by either "strategically ignoring" repressive behavior of staff, or by focusing on the end goal rather than on the means (Ashforth and Anand 2003; Ibsen 2013). When managers ignore, or suppress criticism of, unethical behavior the likelihood of the behavior is reinforced (Hutchinson et al. 2013). Furthermore, past successes of repressive practices are assumed to validate the process through which it was determined (see: rationalization; Ashforth and Anand 2003; Miller 1993); and behavior that was at first personal to individual staff members, becomes the shared norm of a whole team (see: socialization).

Once behavior of a group becomes routinized, it takes more conscious effort to discontinue it than to continue it. Routinizing removes decision points from a process that might otherwise have triggered reflective thought and reduced the salience of repressive practices. Repression can come to be seen as normative, to be adapted, and to be enacted mindlessly (Ashforth and Anand 2003), so that repression not only becomes stable, but eventually not even considered as repressive (Bunderson 2001).

Closely related to routinizing is work fragmentation (Mohr and Horton-Deutsch 2001). In some treatment processes, tasks are so fragmented that staff members cannot recognize the nature or the consequences of their actions. Entire activities can be performed without one individual knowing them entirely (Ashforth and Anand 2003; Bunderson 2001). In this way, staff members may not even know that they are engaging in repressive processes. If a moral issue is not recognized, one cannot engage in moral decision-making processes (Ashforth and Anand 2003; Bandura 1999). Here, Arendt's (1963) famous example of Eichmann is again applicable; Eichmann claimed to not have known that his actions were connected to the extermination of the Jews.

\section{Conclusions Organizational Perspective}

Again, a transactional approach (Sameroff 2009) is apparent. The organizational approach and structure interact with the staff members because of the P-E fit and institutionalization. Staff members differ from each other in their acting because of different education-levels and experiences. Together, with the humanistic and the social psychological approach, it can now be concluded that repression is a series of transactional processes between youth, authority figures, and the organizational approach and structure, characterized by an authority figure intentionally acting in a way that harms the youth, or by an authority figure unlawfully or arbitrarily depriving the youth of liberty or autonomy, fueled by institutionalization and intrapersonal processes in authority figures (fear, rationalization, lack of empathy, dehumanization), mediated by interpersonal processes (socialization and identification).

\section{Discussion}

This scoping review offers a definition of repression, demonstrating that repression in youth care can be seen in the context of a number of transactional processes between youth, staff and organizations (Sameroff 2009). This interplay is shown in Fig. 2. The understanding of these transactional processes is necessary to stimulate professional behavior by staff (Van der Helm and Stams 2012). Negative transactional processes (as opposed to positive transactional processes, such as establishing a working alliance; Roest et al. 2014) may occur between the youth and the staff because of fear, mechanisms of dehumanization, lack of empathy, and rationalization. At the next level, staff members and team leaders influence each other because of the identification and socialization processes. The organizational culture interacts with the team leader and staff members because of the organizational approach (correction and control versus treatment and rehabilitation) and structure of the organization, and subsequently, the $\mathrm{P}-$ E fit. In this triangle of organization, team leader, and staff, institutionalization is possible because these three actors influence whether repressive practices are enacted as a matter of routine, often without conscious thought about their propriety. Consequently, a permissive ethical climate for repression can arise.

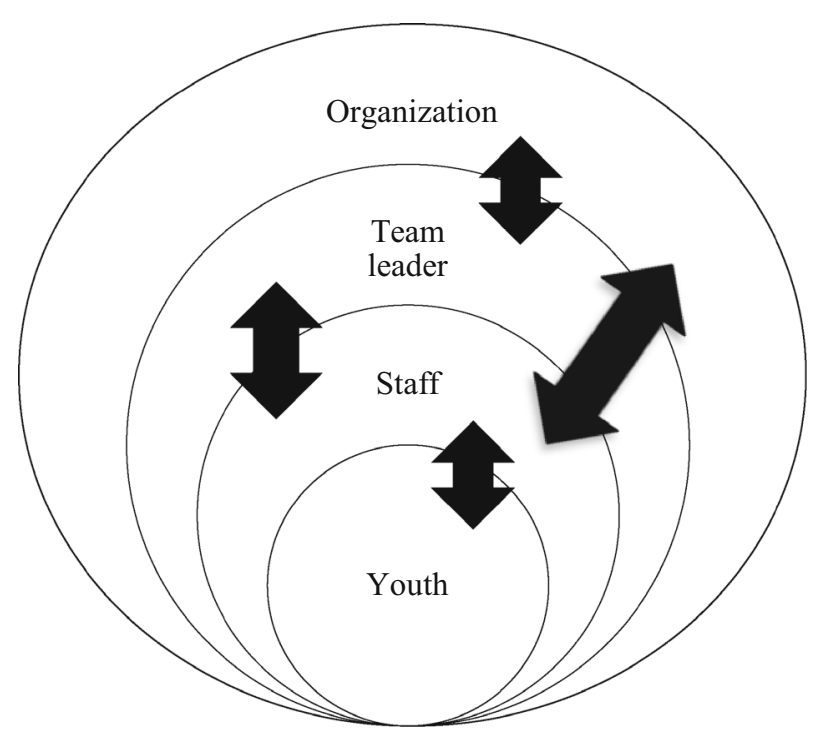

Fig. 2 Transactional processes underlying repression 


\section{Recognizing Repression as a Negative Form of Transactional Processes}

One of the implications of this scoping review is that it offers insight into how to recognize repression from the three perspectives. Repression is a serious trap for staff in residential youth care, because it is hidden in aspects that are an essential part of residential youth care, such as power, structure, and coercion. These aspects become repressive when they are used harmfully, unlawfully, or arbitrarily. This becomes apparent when staff's acting worsens the youth's problems, or when children's rights are violated (for example, when the youth's liberty is restricted without legitimate reason). Arbitrary use of power, structure, and coercion result in youth to see staff's behavior as unpredictable, unfair and unsafe. This may cause reactance and demotivation in youth.

From a humanistic perspective, the hierarchical observation by staff may take invasive forms, such as using camera surveillance, following and restricting youth's movements when they are on leave, or listening to private phone conversations. Management also must be aware of rationalizing arguments, such as security or understaffing, which staff may use to justify their repressive behavior. Furthermore, the normalizing judgment of staff about what they consider either normal or deviant behavior can be repressive-for example, dictating a large amount of rules, together with standardized consequences and punishments, limits the youth's autonomy from a control-oriented perspective. Soft power is apparent in the token economy principle, which rewards discipline and ownership of responsibility, but punishes youth who cannot regulate themselves because they can never achieve these rewards. When youth are unable to achieve rewards, for example due to psychiatric problems or a mild intellectual disability, the token economy system can turn into a punitive cycle. Furthermore, a large amount of punishments can engender a high amount of dehumanization and abuse of power. Thus, management must be aware of punishment by withholding favors in a reward economy (Ibsen 2013).

From a social psychological perspective, a team that discourages interpersonal communication, actively suppresses dissent within the team, dictates youth's behavior (such as walking in line with your hands behind your back), imposes space or time limitations (such as not being allowed to cross a line, without asking, before entering a room; early sleeping hours in the case of trouble) can be seen as repressive. Also, restricting the youth's voice and not taking complaints seriously, characterize repression. A team leader who either stands too far from the team (and in this way creates a permissive ethical climate), or a repressive team leader with whom the team highly identifies, is often leading a repressive team. Furthermore, severe or frequent aggressive incidents and consequently fear of losing control on the ward may cause staff to adopt repressive strategies to regain control. At the level of individual staff members, the manner in which staff members talk about youth may indicate whether they dehumanize youth or empathize with them.

From the organizational perspective, the approach an organization adopts (correction versus rehabilitation) gives a clear indication of the amount of repression in residential youth care. However, it is dependent on the interaction with staff as to whether this approach actually affects the youth. Other repressive characteristics within organizations are a strict hierarchy, highly routinized or fragmented work, unwillingness to receive feedback from external parties, and unlawful use of coercive measures. When a team consists of inexperienced, insufficiently educated, control-oriented staff members, chances are high that the team implements coercive measures, especially when there is a low staffing level or high-risk situation.

\section{Organizational Change}

This scoping review also has implications for modifying a repressive climate in residential youth care. Several programs have been suggested to diminish the amount of coercive measures within residential institutions (Brendtro and Mitchell 2012; Caldwell and Lebel 2010; Green 2001; Lee 2013; Nelson et al. 2010; Romijn and Frederiks 2012). Common features of these programs are stronger connections with the youth, prevention of escalation, focus on the youth's growth and empowerment, staff's knowledge of harmful consequences of coercion, and an approach that is supported by, and directed to, the whole organization.

Miller et al. (2006) are one of the few who examined the effectiveness of their method to reduce coercive measures. They tested a milieu intervention focusing on positive behavioral support (Positive Behavioral Intervention and Support [PBIS]; Jolivette and Nelson 2010; Sprague et al. 2013), along with the efforts of a restraint-reduction committee; they found a reduction in restraint rates of $59 \%$ over 33 months. The study points to the need for leadership and an organizational culture that desires to use physical restraints as a last-resort safety intervention. Furthermore, they found that staff's behavior and beliefs could change through ongoing staff training and supervision programs, which was also stated by Delaney (2001). Miller et al. (2006) reported from anecdotal feedback that antecedents of reduction in restraints were improved relationships between staff and client, more effective training, better oversight, and even a shift away from the old culture (in which restraint was a more acceptable form of intervention) by some staff. Consequently, staff experienced 
more feelings of control and less stress about their job (Miller et al. 2006; Van der Helm and Stams 2012).

Argyris (1982) argued that people are often unaware of the theories that drive their actions (theory-in-use), and that their theory-in-use is often not the same as the world's views and values that people believe their behavior is based on (espoused theory). Researchers have also found that moral judgments are not solely the product of conscious reasoning or rationalization on the basis of explicitly understood moral principles (Hauser et al. 2007; Navarick 2013). This suggests that to change behavior of staff in residential settings the staff should first be aware of factors that determine their behavior, reflect on this, and then change these factors as a result. This would constitute double-loop learning (Argyris 1982).

\section{Preventing and Countering Repression on Staff Level}

Another implication of this scoping review pertains to the way repression can be prevented or countered. Because of the persistent character of repression and its negative effect on staff (Lambert et al. 2011), as well as youth (Heynen et al. 2016), prevention is better than cure. To prevent repression, the organizational culture, ethical values, and awareness of repression must be institutionalized at all levels of residential youth care (individual treatment programs of youth, team behavior, organization, and society), and incorporated into everyday decision-making and action. Senior team members and team leaders can serve as role models for new team members, so that socialization occurs under the correct influence. Supervision can help prevent acting on negative feelings (such as fear and anger); and through the use of reflection, possible harm caused by repressive acting can be prevented (Heneghan et al. 2014; Paterson 2011; Stams and Van der Helm 2016). Seniors and team leaders should prepare to handle conflict between the new organizational culture and staff members of the old organizational culture, who sometimes view repression as "the way we do things around here" (Schein 2004, p. 13). Transformational leadership (using inspiration and innovation to motivate staff members and to increase staff's awareness of task importance and values) by management and team leaders is needed to counteract punitive attitudes and feelings of unsafety among staff members, as well as to support staff members in performing their difficult tasks in the group (Van der Helm et al. 2006).

Organizations should pay particular attention to their staff selection. It is important that staff members have sufficient knowledge of psychopathology, and how this influences youth's behavior. Furthermore, a diverse team (in age, experience, gender, and culture) is desirable because it diminishes groupthink. Staff should be well trained in programs that offer alternatives to coercive measures in threatening situations, such as de-escalation programs (NICE 2005), Non-Violent Resistance (Omer 2004), and PBIS (Horner 2010; Sprague et al. 2013). Furthermore, special training for staff offers promising results (TOP-PM training or de-escalation officers; Aseib et al. 2010; Van der Helm and Schaftenaar 2014).

As Ashforth and Anand (2003) stated in their research on the intertwined processes that cause corruption in organizations, the system trumps the individual staff member when it comes to repression. Only systemic responses can reverse systemic normalization, because it is extremely difficult for individual employees to counter repression once it is institutionalized. But, it is also a big challenge for management, as it requires a significant organizational change effort when repression is part of the organizational or group culture. Furthermore, because managers are part of the repressive system and subject to the same normalizing pressures as other staff members, it is suggested that creating the needed radical change requires the involvement of outsiders who have not been part of the system. Where no standard solutions are available to change a dynamic and complex environment, triple-loop learning should be stimulated through the creation of continuous feedback (Tosey et al. 2011). This can be achieved by periodically measuring living group climate and working climate, together with feedback and goal setting (Van der Helm et al. 2015). Giving and receiving feedback, and reflecting on results in a constructive, nonthreatening manner are critical in quality-improvement efforts (Petti et al. 2001).

By concluding that it is extremely difficult for individual staff members to counter repressive acting on their ward, and that change on a larger scale is needed, staff members are not released from responsibility. As the literature revealed, conscious effort is necessary to empathize with youth in residential care. This empathy is crucial to prevent or to diminish dehumanization. Furthermore, staff should continuously reflect on their own, as well as their colleagues', acting. Only when moral issues are recognized will it be possible to discuss and to change behavior. At the individual level, staff members are then able to counter routinized behavior and to act less repressively. Team leaders and psychologists can have a facilitating and stimulating role in this process. They can organize team meetings with themes that relate to repression (i.e. rules, punishments, coercive measures, moral issues, ethics, and group climate), and they can stimulate reflection in staff members on a regular basis by asking whether there are less invasive ways to reach the same goal. Reflection and communication at all levels should be guiding principles. Besides team leaders and psychologists, it can be helpful if 
staff members have access to confidential advice of ethics officers, while complaints should be addressed correctly and swiftly.

\section{Diminished Repression in a Secure Setting: An Example}

Polvere (2014) indicated that, to effectively address institutional oppression, the core characteristics of institutions must change, including systems that reward compliance rather than the development of self-determined goals and agency. One successful example of such a humanizing approach is described by Anthonio (2005), who worked as the newly hired director of a forensic psychiatric hospital in the Netherlands. His task was to manage this institution through a crisis (e.g. two escapes, several suicides, assumed intimate relationships between female staff and patients, and high rates of staff absence due to sickness), and to change the repressive culture that was driven by fear. Patients were humiliated, neglected, bullied, and physically abused. Anthonio chose two approaches to change the organizational culture: humanizing treatment and fight against inhumane practices. Reflection and communication at all levels were guiding principles. This resulted in an open door policy, patients having their own key, an enriched activity program, and patient participation in creating policies. Although patients received more responsibilities, no severe incidents occurred. On the contrary, the amount of restraints and seclusions diminished by $50 \%$, and the amount of recidivism during readjustment phases diminished from 27 to $3.3 \%$. This example illustrates how a humanizing approach, by focusing on reflection and communication at all levels of the organization, stimulates the patients' autonomy and decreases the amount of coercion.

\section{Limitations}

An important limitation of the current review is that the extensive literature search did not result in literature about how youth themselves experience repression inside secure residential institutions. Therefore, this scoping review considered mainly staff and organizational factors influencing repression. This provides an important implication for future research; the described characteristics and processes of repression should be examined with youth's experiences. Furthermore, although the humanistic approach indicated that the limitation of autonomy and freedom was an important aspect in the understanding of repression, the organizational literature that was found with the search strings focused mainly on the use of coercive measures. This dimension of repression deserves more attention in future research.

Another limitation of this scoping review was that the included literature did not focus exclusively on residential youth care. A considerable number of the included studies were conducted within adult, educational, correctional, or (forensic) psychiatry settings. However, the described processes in this diverse literature were considered to be comparable, which was why this literature was still included. While reviewing the articles and book chapters, more importance was attached to the literature about residential youth care institutions than to literature about other settings.

No structured approach to evaluate the quality of the included sources has been used, in order to include as much of the available research on repression in residential youth care. Still, $80 \%$ of the included articles were published in peer-reviewed journals. The majority of the included sources is theoretical, which indicates that empirical research on repression in residential youth care is hardly available. The few empirical studies on repression in residential youth care are mostly cross-sectional instead of prospective-longitudinal, neglecting the multi-level data structure and therefore statistical dependency (i.e. participants are nested within living groups, particular units and teams), using samples of convenience, and assessment instruments that underrepresent repression as a construct (construct underrepresentation), confuse repression with related concepts (construct overrepresentation) or lack reliability (Tonkin 2015).

\section{Conclusion}

To date, the term repression was a catchall concept for a variety of negative processes in residential settings. This scoping review offers a definition of repression based on humanistic, social psychological, and organizational perspectives, and provides insight into the several transactional processes between youth, staff, and organization underlying repression. Despite the limitations of this study, these insights can be used to prevent repression, or to recognize and counter repression, which begins with an awareness of repression, and reflection on staff's behavior. Further research is necessary into when structure, power and coercion are experienced arbitrarily by youth. Furthermore, it should be investigated in which specific situations, structure and staff's behavior violate children's rights. Practice based research on the subject should be joined with evidence based efforts to minimize repression in residential youth care, in order to provide a safe upbringing and treatment environment, where children's rights are respected. 
Acknowledgments Affiliations: This study was made possible by the support of the Reformed Civil Orphanage (Gereformeerd Burger Weeshuis), Rotterdam, The Netherlands.

\section{References}

Abrams, L. S., Kim, K., \& Anderson-Nathe, B. (2005). Paradoxes of treatment in juvenile corrections. Child \& Youth Care Forum, 34(1), 7-25. doi:10.1007/s10566-004-0879-3.

Adame, A. L., \& Leitner, L. M. (2008). Breaking out of the mainstream: The evolution of peer support alternatives to the mental health system. Ethical Human Psychology and Psychiatry, 10(3), 146-162. doi:10.1891/1559-4343.10.3.146.

Akers, R. (1977). Deviant behaviour: A social learning approach (2nd ed.). Belmont, CA: Wadsworth.

American Psychiatric Nurses Association. (2001). American Psychiatric Nurses Association position statement on the use of seclusion and restraint. Journal of the American Psychiatric Nurses Association, 7(4), 130-133. doi:10.1067/mpn.2001.117878.

Anckarsäter, H., Nilsson, T., Ståhlberg, O., Gustafson, M., Saury, J.M., Råstam, M., \& Gillberg, C. (2007). Prevalences and configurations of mental disorders among institutionalized adolescents. Developmental Neurorehabilitation, 10(1), 57-65. doi:10.1080/13638490600864157.

Anthonio, G. G. (2005). Humanisering van een justitiële organisatie. Utrecht: Universiteit voor Humanistiek.

Apter, M. J. (2003). Motivational styles and positioning theory. In R. Harre \& F. Moghaddam (Eds.), The self and others: Positioning individuals and groups in personal, political, and cultural contexts (pp. 15-27). Westport, CT: Praeger Publishers.

Arendt, H. (1963). Eichmann in Jerusalem: A report on the banality of evil. New York: Penguin Books.

Argyris, C. (1982). Reasoning, learning, and action: Individual and organizational (1st ed.). San Francisco: Jossey-Bass.

Arksey, H., \& O'Malley, L. (2005). Scoping studies: Towards a methodological framework. International Journal of Social Research Methodology, 8(1), 19-32. doi:10.1080/1364557032000119616.

Aseib, S., Van der Helm, G. H. P., Ko, J., \& Boekee, I. (2010). Handleiding training TOP_PM'ers. Leiden: Hogeschool Leiden.

Ashforth, B. E., \& Anand, V. (2003). The normalization of corruption in organizations. Research in Organizational Behavior, 25, 1-52. doi:10.1016/S0191-3085(03)25001-2.

Bandura, A. (1999). Moral disengagement in the perpetration of inhumanities. Personality and Social Psychology Review, 3(3), 193-209. doi:10.1207/s15327957pspr0303_3.

Bandura, A. (2002). Selective moral disengagement in the exercise of moral agency. Journal of Moral Education, 31(2), 101-119. doi:10.1080/0305724022014322.

Baron-Cohen, S. (2003). The essential difference: Men, women, and the extreme male brain. London: Penguin.

Baumeister, R. F., \& Campbell, W. K. (1999). The intrinsic appeal of evil: Sadism, sensational thrills, and threatened egotism. Personality \& Social Psychology Review, 3(3), 210-221.

Bedau, H. A., \& Kelly, E. (2015). Punishment. In E. N. Zalta (Ed.), The stanford encyclopedia of philosophy (Fall 2015 ed.). http:// plato.stanford.edu/archives/fall2015/entries/punishment/

Blevins, K. R., Listwan, S. J., Cullen, F. T., \& Jonson, C. L. (2010). A general strain theory of prison violence and misconduct: An integrated model of inmate behavior. Journal of Contemporary Criminal Justice, 26(2), 148-166. doi:10.1177/1043986209359369.

Bloom, P. (2013). Just babies: The origins of good and evil. New York: Crown Publishers.

Boehm, C. (2012). Moral origins: The evolution of virtue, altruism, and shame. New York: Basic Books.
Bowers, L., Wright, S., \& Stewart, D. (2014). Patients subject to high levels of coercion: Staff's understanding. Issues in Mental Health Nursing, 35(5), 364-371. doi:10.3109/01612840.2013.871088.

Brendtro, L. K., \& Mitchell, M. L. (2012). Building respectful connections. Reclaiming Children and Youth, 20(4), 5-10.

Brink, D. (2014). Mill's moral and political philosophy. In E. N. Zalta (Ed.), The Stanford encyclopedia of philosophy (Fall 2014 ed.). http://plato.stanford.edu/archives/fall2014/entries/mill-moralpolitical/

Browne, K. (2009). The risk of harm to young children in institutional care. Save the Children, doi:10.1177/1524838005283696.

Bunderson, J. S. (2001). Normal injustices and morality in complex organizations. Journal of Business Ethics, 33(3), 181-190. doi:10.1023/A:1017566602938.

Busch, A. B., \& Shore, M. F. (2000). Seclusion and restraint: A review of recent literature. Harvard Review of Psychiatry, 8(5), 261-270.

Calder, T. (2014). The concept of evil. In E. N. Zalta (Ed.), The Stanford encyclopedia of philosophy (Fall 2015 ed.). http://plato. stanford.edu/archives/fall2015/entries/concept-evil/.

Caldwell, B. B., \& Lebel, J. (2010). Reducing restraint and seclusion: How to implement organizational change. Children's VOICE, March/April(April), 10-14

Carter, I. (2012). Positive and negative liberty. In E. N. Zalta (Ed.), The Stanford Encyclopedia of Philosophy (Spring 2012 ed.). http://plato.stanford.edu/archives/spr2012/entries/liberty-positivenegative/

Chow, W. S., \& Priebe, S. (2013). Understanding psychiatric institutionalization: A conceptual review. BioMed Central Psychiatry, 13(169), 1-14. doi:10.1186/1471-244X-13-169.

Colins, O., Vermeiren, R., Vreugdenhil, C., Van den Brink, W., Doreleijers, T., \& Broekaert, E. (2010). Psychiatric disorders in detained male adolescents: A systematic literature review. The Canadian Journal of Psychiatry, 55(4), 255-263.

Colton, M. (2002). Factors associated with abuse in residential child care institutions. Children and Society, 16(1), 33-44. doi:10. 1002/chi.683.

Colvin, M. (1992). The penitentiary in crisis: From accommodation to riot in New Mexico. Albany: State University of New York Press.

Craig, S. C. (2004). Rehabilitation versus control: An organizational theory of prison management. The Prison Journal, 84(4), 92S114S. doi:10.1177/0032885504269394.

Crewe, B. (2009). Soft power in prison: Implications for staff-prisoner relationships, liberty and legitimacy. European Journal of Criminology, 8(6), 455-468. doi:10.1177/1477370811413805.

Damasio, A. R. (1994). Descartes' error: Emotion, reason and the human brain. New York: Avon Books.

Davidson, J., McCullough, D., Steckley, L., \& Warren, T. (2005). Holding safely: A guide for residential child care practitioners and managers about physically restraining children and young people. Glasgow: Scottish Institute of Residential Child Care.

Day, A., Daffern, M., \& Simmons, P. (2010). Use of restraint in residential care settings for children and young people. Psychiatry, Psychology and Law, 17(2), 230-244. doi:10.1080/ 13218710903433964.

De Kogel, C. H., \& Nagtegaal, M. H. (2008). Toezichtprogramma's voor delinquenten en forensisch psychiatrische patiënten: Effectiviteit en veronderstelde werkzame mechanismen. Meppel: Boom Juridische Uitgevers.

De Lange, M., Addink, A., Haspels, M., \& Geurts, E. (2015). Richtlijn residentiële jeugdhulp voorjeugdhulp en jeugdbescherming. Utrecht: Nederlands Jeugdinstitituut.

De Swart, J. J. W., Van den Broek, H., Stams, G. J. J. M., Asscher, J. J., Van der Laan, P. H., Holsbrink-Engels, G. A., \& Van der Helm, G. H. P. (2012). The effectiveness of institutional youth 
care over the past three decades: A meta-analysis. Children and Youth Services Review, 34(9), 1818-1824. doi:10.1016/j.child youth.2012.05.015.

De Valk, S., Van der Helm, G. H. P., Beld, M., Schaftenaar, P., Kuiper, C., \& Stams, G. J. J. M. (2015). Does punishment in secure residential youth care work? An overview of the evidence. Journal of Children's Services, 10(1), 3-16.

De Waal, F. (2010). The age of empathy: Nature's lessons for a kinder society. New York: Harmony Books.

Delaney, K. R. (2001). Developing a restraint-reduction program for child: Adolescent inpatient treatment. Journal of Child and Adolescent Psychiatric Nursing, 14(3), 128-140.

Den Ouden, H. E. M., Daw, N. D., Fernandez, G., Elshout, J. A., Rijpkema, M., Hoogman, M., et al. (2013). Dissociable effects of dopamine and serotonine on reversal learning. Neuron, 80(4), 1090-1100.

Dilulio, J. J. (1987). Governing prisons: A comparative study of correctional management. New York: Free Press.

Du Plessis, R. (2013). Constructing patient-psychiatrist relations in psychiatric hospitals: The role of space and personal action. Social Semiotics, 23(3), 424-443. doi:10.1080/10350330.2012. 739003.

Dworkin, G. (2014). Paternalism. In E. N. Zalta (Ed.), The stanford encyclopedia of philosophy (Summer 2014 ed.). http://plato. stanford.edu/archives/sum2014/entries/paternalism/

Dye, M. H. (2010). Deprivation, importation, and prison suicide: The combined effects of institutional conditions and inmate composition. Journal of Criminal Justice, 38, 796-806.

Edwards, J., Cable, D., Williamson, I., Lambert, L., \& Shipp, A. (2006). The phenomenology of fit: Linking the person and environment to the subjective experience of person-environment fit. Journal of Applied Psychology, 91, 802-827.

Elling Ellingsen, K., Berge, K., \& Lungwitz, D. (2011). Rule of lawwishful thinking? Exemptions from educational requirements and the use of coercion against people with intellectual disability. Scandinavian Journal of Disability Research, 13(2), 151-166. doi:10.1080/15017419.2010.490755.

Fazel, S., Doll, H., \& Långström, N. (2008). Mental disorders among adolescents in juvenile detention and correctional facilities: A systematic review and metaregression analysis of 25 surveys. Journal of the American Academy of Child and Adolescent Psychiatry, 47(9), 1010-1019. doi:10.1097/CHI.ObO13e31 817 eecf3.

Festinger, L. A. (1957). A theory of cognitive dissonance. Stanford, CA: Stanford University Press.

Fishbein, D., \& Sheppard, M. (2006). Assessing the role of neuropsychological functioning in inmates' treatment response. https://www.ncjrs.gov/App/Publications/abstract.aspx?ID=237 914

Fluttert, F. A. J. (2010). Management of inpatient aggression in forensic mental health nursing: The application of the Early Recognition Model. Utrecht: University of Utrecht.

Foucault, M. (1977). Discipline and punish: The birth of the prison. London: Allen Lange, Penguin.

Frijda, N. H. (2007). The laws of emotions. Mahwah: Lawrence Erlbaum Associates Publishers.

Gelkopf, M., Roffe, Z., Behrbalk, P., Melamed, Y., Werbloff, N., \& Bleich, A. (2009). Attitudes, opinions, behaviors, and emotions of the nursing staff toward patient restraint. Issues in Mental Health Nursing, 30(12), 758-763. doi:10.3109/01612840903159777.

Geller, J. L., Fisher, W. H., Grudzinskas, A. J., Clayfield, J. C., \& Lawlor, T. (2006). Involuntary outpatient treatment as "deinstitutionalized coercion": The net-widening concerns. International Journal of Law and Psychiatry, 29(6), 551-562. doi:10. 1016/j.ijlp.2006.08.003.
Gilburt, H., Slade, M., Rose, D., Lloyd-Evans, B., Johnson, S., \& Osborn, D. P. J. (2010). Service users' experiences of residential alternatives to standard acute wards: Qualitative study of similarities and differences. British Journal of Psychiatry, 197, 26-32. doi:10.1192/bjp.bp.110.081075.

Goffman, E. (1961). Asylums: Essays on the social situations of mental patients and other inmates. New York: Doubleday Anchor.

Goodstein, L., MacKenzie, D. L., \& Shotland, R. L. (1984). Personal control and inmate adjustment to prison. Criminology, 22(3), 343-369.

Grant, M. J., \& Booth, A. (2009). A typology of reviews: An analysis of 14 review types and associated methodologies. Health Information and Libraries Journal, 26, 91-108. doi:10.1111/j. 1471-1842.2009.00848.x.

Green, R. (2001). The explosive child. New York: Harper Collins.

Gutting, G. (2014). Michel Foucault. In E. N. Zalta (Ed.), The Stanford encyclopedia of philosophy (Winter 2014 ed.). http:// plato.stanford.edu/archives/win2014/entries/foucault/

Haley, H., \& Sidanius, J. (2005). Person-organization congruence and the maintenance of group-based social hierarchy: A social dominance perspective. Group Processes \& Intergroup Relations, 8(2), 187-203. doi:10.1177/1368430205051067.

Halpern, J., \& Weinstein, H. M. (2004). Rehumanizing the other: Empathy and reconciliation. Human Rights Quarterly, 26(3), 561-583. doi:10.1353/hrq.2004.0036.

Haney, C. (2006). The wages of prison overcrowding: Harmful psychological consequences and dysfunction. Journal of Law and Policy, 22(1), 265-293.

Haney, C., Banks, W. C., \& Zimbardo, P. G. (1973). A study of prisoners and guards in a simulated prison. Naval Research Review, 30, 4-17.

Hanrath, J. J. (2013). De groepsleider als evenwichtskunstenaar. Utrecht: Universiteit Utrecht.

Haque, O. S., \& Waytz, A. (2012). Dehumanization in medicine. Perspectives on Psychological Science, 7(2), 176-186. doi:10. 1177/1745691611429706.

Harvey, M. G., Heames, J. T., Richey, R. G., \& Leonard, N. (2006). Bullying: From the playground to the boardroom. Journal of Leadership \& Organizational Studies, 12(4), 1-11. doi:10.1177/ 107179190601200401.

Haslam, N. (2006). Dehumanization: An integrative review. Personality and Social Psychology Review, 10(3), 252-264.

Haslam, S. A. (2014). Making good theory practical: Five lessons for an Applied Social Identity Approach to challenges of organizational, health, and clinical psychology. The British Journal of Social Psychology, 53(1), 1-20. doi:10.1111/bjso.12061.

Haslam, S. A., \& Reicher, S. D. (2012). Contesting the "Nature" of conformity: What Milgram and Zimbardo's studies really show. PLoS Biology, 10(11), 1-4. doi:10.1371/journal.pbio.1001426.

Hastings, R. P. (2005). Staff in special education settings and behaviour problems: Towards a framework for research and practice. Educational Psychology, 25(2-3), 207-221. doi:10. 1080/0144341042000301166.

Hauser, M., Cushman, F., Young, L., Jin, R. K. X., \& Mikhail, J. (2007). A dissociation between moral judgments and justifications. Mind and Language, 22(1), 1-21.

Heneghan, C., Wright, J., \& Watson, G. (2014). Clinical psychologists' experiences of reflective staff groups in inpatient psychiatric settings: A mixed methods study. Clinical Psychology \& Psychotherapy, 21(4), 324-340. doi:10.1002/cpp.1834.

Heynen, E., Van der Helm, G. H. P., Cima, M., Stams, G. J. J. M., \& Korebrits, A. (2016). The relation between living group climate, aggression and callous-unemotional traits in delinquent boys in detention. International Journal of Offender Therapy and 
Comparative Criminology, 1, 1-18. doi:10.1177/0306624X166 30543.

Hobbes, T. (1651). Leviathan. London, England: Andrew Crooke.

Höfte, S. J. C., Van der Helm, G. H. P., \& Stams, G. J. J. M. (2012). Het internationaal recht en knelpunten in de gesloten jeugdzorg: Adviezen voor de praktijk. Justitiële Verkenningen, 38(6), 84-99.

Holmes, D., \& Murray, S. J. (2011). Civilizing the "Barbarian": A critical analysis of behaviour modification programmes in forensic psychiatry settings. Journal of Nursing Management, 19(3), 293-301. doi:10.1111/j.1365-2834.2011.01207.x.

Horner, R. (2010). The importance of coaching in implementation of evidence-based practices. www.pbis.org

Huckshorn, K. A., LeBel, J., \& Jacobs, H. E. (2014). An organizational approach to reducing and preventing restraint and seclusion use with people with acquired brain injury. Neurorehabilitation, 34, 671-680. doi:10.3233/NRE-141073.

Hutchinson, M., Jackson, D., Walter, G., \& Cleary, M. (2013). Coercion and the corruption of care in mental health nursing: Lessons from a case study. Issues in Mental Health Nursing, 34, 476-480. doi:10.3109/01612840.2013.792168.

Ibsen, A. Z. (2013). Ruling by favors: Prison guards' informal exercise of institutional control. Law \& Social Inquiry, 38(2), 342-363.

Inspectie Jeugdzorg, \& Inspectie voor de Gezondheidszorg (2015). Toetsingskader nieuwe toetreders jeugdhulp. Utrecht.

Jacob, J. D., \& Foth, T. (2013). Expanding our understanding of sovereign power: On the creation of zones of exception in forensic psychiatry. Nursing Philosophy, 14, 178-185.

Jacob, J. D., Holmes, D., \& Buus, N. (2008). Humanism in forensic psychiatry: The use of the tidal nursing model. Nursing Inquiry, 15(3), 224-230. doi:10.1111/j.1440-1800.2008.00420.x.

Janis, I. L., \& Mann, L. (1977). Decision making: A psychological analysis of conflict, choice, and commitment. New York: Free Press.

Jolivette, K., \& Nelson, C. M. (2010). Adapting positive behavioral interventions and supports for secure juvenile justice settings: Improving facility-wide behavior. Behavioral Disorders, 36(1), $28-42$.

Kennedy, S. S., \& Mohr, W. K. (2001). A prolegomenon on restraint of children: Implicating constitutional rights. American Journal of Orthopsychiatry, 71(1), 26-37.

Keysers, C. (2011). The empathic brain-How the discovery of mirror neurons changes our understanding of human nature. https://books.google.nl/books?id=Ag9cAwAAQBAJ\&pg=PA234 $\& \mathrm{dq}=$ the + empathic + brain + keysers $\& \mathrm{hl}=\mathrm{nl} \& \mathrm{sa}=\mathrm{X} \&$ redir_esc $=$ $\mathrm{y} \# \mathrm{v}=$ onepage $\& \mathrm{q}=$ the $\% 20$ empathic $\% 20 \mathrm{brain} 20$ keysers $\& \mathrm{f}=$ false

Knorth, E. J., Harder, A. T., Zandberg, T., \& Kendrick, A. J. (2008). Under one roof: A review and selective meta-analysis on the outcomes of residential child and youth care. Children and Youth Services Review, 30, 123-140. doi:10.1016/j.childyouth.2007.09.001.

Koekkoek, B., Hutschemaekers, G., Van Meijel, B., \& Schene, A. (2011). How do patients come to be seen as "difficult"?: A mixed-methods study in community mental health care. Social Science and Medicine, 72(4), 504-512. doi:10.1016/j.socscimed. 2010.11.036.

Kopelman, L. M. (1997). The best-interests standard as threshold, ideal, and standard of reasonableness. The Journal of Medicine and Philosophy, 22(3), 271-289. doi:10.1093/jmp/22.3.271.

Kteily, N., Bruneau, E., Waytz, A., \& Cotterill, S. (2015). The ascent man: Theoretical and empirical evidence for blatant dehumanization. Journal of Personality and Social Psychology,. doi:10. 1037/pspp0000048.

Kurzban, R., DeScioli, P., \& O'Brien, E. (2006). Audience effects on moralistic punishment. Evolution and Human Behavior, 28(2), 75-84. doi:10.1016/j.evolhumbehav.2006.06.001.
Laing, R. D. (1974). The politics of experience and the bird of paradise. Harmondsworth: Penguin.

Lambert, E. G., Altheimer, I., Hogan, N. L., \& Barton-Bellessa, S. M. (2011). Correlates of correctional orientation in a treatmentoriented prison: A partial test of person-environment fit theory. Criminal Justice and Behavior, 38(5), 453-470. doi:10.1177/ 0093854811400716.

Lambert, E. G., Barton-Bellessa, S. M., \& Hogan, N. L. (2015). The consequences of emotional burnout among correctional staff. SAGE Open, 5(2), 1-15. doi:10.1177/2158244015590444.

Lambrechts, G., Kuppens, S., \& Maes, B. (2009). Staff variables associated with the challenging behaviour of clients with severe or profound intellectual disabilities. Journal of Intellectual Disability Research, 53(7), 620-632. doi:10.1111/j.1365-2788. 2009.01162.x.

Lammers, J., \& Stapel, D. A. (2011). Power increases dehumanization. Group Processes \& Intergroup Relations, 14(1), 113-126. doi:10.1177/1368430210370042.

Lammers, J., Stapel, D. A., \& Galinsky, A. D. (2010). Power increases hypocrisy: Moralizing in reasoning, immorality in behavior. Psychological Science, 21(5), 737-744. doi:10.1177/ 0956797610368810.

Larsen, I. B., \& Terkelsen, T. B. (2013). Coercion in a locked psychiatric ward: Perspectives of patients and staff. Nursing Ethics, 21(4), 426-436. doi:10.1177/0969733013503601.

LeBel, J., Huckshorn, K. A., \& Caldwell, B. (2010). Restraint use in residential programs: Why are best practices ignored? Child Welfare, 89(2), 169-187.

Lee, S. (2013). The problem with punishment. Reclaiming Children and Youth, 21(4), 50-54.

Lipsey, M. W. (2009). The primary factors that characterize effective interventions with juvenile offenders: A meta-analytic overview. Victims \& Offenders, 4(2), 124-147. doi:10.1080/1556 4880802612573.

Listwan, S. H., Colvin, M., Hanley, D., \& Flannery, D. (2010). Victimization, social support, and psychological well-being: A study of recently released prisoners. Criminal Justice and Behavior, 37(10), 1140-1159. doi:10.1177/0093854810376338.

Listwan, S. J., Sullivan, C. J., Agnew, R., Cullen, F. T., \& Colvin, M. (2013). The pains of imprisonment revisited: The impact of strain on inmate recidivism. Justice Quarterly, 30(1), 144-168. doi:10.1080/07418825.2011.597772.

MacKenzie, D. L. (1997). Criminal justice and crime prevention. In L. W. Sherman, D. Gottfredson, D. L. MacKenzie, J. Eck, P. Reuter, \& S. Bushway (Eds.), Preventing crime: What works, what doesn't, what's promising (pp. 1-76). Washington, DC: NIJ.

Marr, K., \& Ezeife, A. (2006). Empathy, authoritarianism, and recalled parental attitudes in child and youth workers. Relational Child and Youth Care Practice, 21(1), 26-37.

Mercer, J. (2013). Holding therapy in Britain: Historical background, recent events, and ethical concerns. Adoption \& Fostering, 37(2), 144-156. doi:10.1177/0308575913490498.

Milgram, S. (1963). Behavioural study of obedience. Journal of Abnormal Social Psychology, 67, 371-378.

Mill, J. S. (1859). On liberty. London: Longman, Roberts \& Green.

Miller, D. (1993). The architecture of simplicity. Academy of Management Review, 18(1), 116-138.

Miller, J. A., Hunt, D. P., \& Georges, M. A. (2006). Reduction of physical restraints in residential treatment facilities. Journal of Disability Policy Studies, 16(4), 202-208. doi:10.1177/ 10442073060160040101.

Miller, W. R., \& Rollnick, S. (2002). Motivational interviewing: Preparing people for change (2nd ed.). New York: Guilford.

Modlin, H. (2011). Meaning-making: Another perspective. Relational Child and Youth Care Practice, 26(3), 5-13. 
Modlin, H. (2015). Child and youth care through a constructivedevelopmental lens. Scottish Journal of Residential Child Care, 14(1), 1-11.

Mohr, W. K., \& Horton-Deutsch, S. (2001). Malfeasance and regaining nursing's moral voice and integrity. Nursing Ethics, $8(1), 19-35$.

Mussweiler, T., \& Ockenfels, A. (2013). Similarity increases altruistic punishment in humans. Proceedings of the National Academy of Sciences, 110(48), 19318-19323. doi:10.1073/ pnas. 1215443110.

Navarick, D. J. (2013). Moral ambivalence: Modeling and measuring bivariate evaluative processes in moral judgment. Review of General Psychology, 17(4), 443-452. doi:10.1037/a0034527.

Nelson, C. M., Jolivette, K., Leone, P. E., \& Mathur, S. R. (2010). Meeting the needs of at-risk and adjudicated youth with behavioral challenges: The promise of juvenile justice. Behavioral Disorders, 36(1), 70-80.

NICE (2005). Clinical practice guidelines for violence. The shortterm management of disturbed/violent behaviour in psychiatric in-patient and emergency departments guideline.

Nye, J. (2004). Soft power: The means to success in world politics. New York: Public Affairs.

Omer, H. (2004). Nonviolent resistance. A new approach to violent and self-destructive children. Cambridge: Cambridge University Press.

Parhar, K. K., Wormith, J. S., Derkzen, D. M., \& Beauregard, A. M. (2008). Offender coercion in treatment: A meta-analysis of effectiveness. Criminal Justice and Behavior, 35(9), 1109-1135. doi: $10.1177 / 0093854808320169$.

Paterson, B. (2011). How corrupted cultures lead to abuse of restraint interventions. Learning Disability Practice, 14(7), 24-28.

Paterson, B., \& Duxbury, J. (2007). Restraint and the question of validity. Nursing Ethics, 14(4), 535-545.

Petti, T. A., Mohr, W. K., Somers, J. W., \& Sims, L. (2001). Perceptions of seclusion and restraint by patients and staff in an intermediate-term care facility. Journal of Child and Adolescent Psychiatric Nursing, 14(3), 115-117.

Pinker, S. (2011). The better angels of our nature: Why violence has declined. New York, NY: Viking.

Polvere, L. (2014). Agency in institutionalised youth: A critical inquiry. Children and Society, 28(3), 182-193. doi:10.1111/chso.12048.

Popma, A., \& Raine, A. (2006). Will future forensic assessment be neurobiologic? Child and Adolescent Psychiatric Clinics of North America, 15(2), 429-444. doi:10.1016/j.chc.2005.11.004.

Prinsen, E. J. D., \& Van Delden, J. J. M. (2009). Can we justify eliminating coercive measures in psychiatry? Journal of Medical Ethics, 35(1), 69-73. doi:10.1136/jme.2007.022780.

Pritikin, M. H. (2009). Is prison increasing crime? Wisconsin Law Review, 2008, 1049-1108.

Quirk, A., Lelliott, P., \& Seale, C. (2006). The permeable institution: An ethnographic study of three acute psychiatric wards in London. Social Science and Medicine, 63(8), 2105-2117. doi:10. 1016/j.socscimed.2006.05.021.

Raine, A. (2013). The anatomy of violence: The biological roots of crime. New York, NY: Pantheon Books.

Regan, K. (2010). Trauma informed care on an inpatient paediatric psychiatric unit and the emergence of ethical dilemmas as nurses evolved their practice. Issues in Mental Health Nursing, 31(3), 216-222. doi:10.3109/01612840903315841.

Repression. (n.d.). Retrieved January 6, 2016, from http://www. merriam-webster.com/dictionary/repression

Rhodes, L. A. (2007). Supermax as a technology of punishment. Social Research: An International Quarterly, 74(2), 547-567.

Ridgway, P. (2001). Restoring psychiatric disability: Learning from first person recovery narratives. Psychiatric Rehabilitation Journal, 24(4), 335-343.
Rodgers, A. B., Morgan, C. P., Leu, N. A., \& Bale, T. L. (2015). Transgenerational epigenetic programming via sperm microRNA recapitulates effects of paternal stress. Proceedings of the National Academy of Sciences, 112(44), 13699-13704. doi:10. 1073/pnas.1508347112.

Roest, J. J., Van der Helm, G. H. P., \& Stams, G. J. J. M. (2016). The relation between therapeutic alliance and treatment motivation in residential youth care: A crossed-lagged panel analysis. Child and Adolescent Social Work Journal, . doi:10.1007/s10560-016-0438-4.

Roest, J. J., Van der Helm, G. H. P., Strijbosch, E. L. L., Van Brandenburg, M., \& Stams, G. J. J. M. (2014). Measuring therapeutic alliance with children in residential treatment and therapeutic day care: A validation study of the Children's Alliance Questionnaire. Research on Social Work Practice,. doi: $10.1177 / 1049731514540478$.

Romijn, A., \& Frederiks, B. J. M. (2012). Restriction on restraints in the care for people with intellectual disabilities in the Netherlands: Lessons learned from Australia, UK, and United States. Journal of Policy and Practice in Intellectual Disabilities, 9(2), 127-133. doi:10.1111/j.1741-1130.2012.00345.x.

Russett, B., \& Oneil, J. R. (2001). Triangulating peace: Democracy, interdependence, and international organisations. New York: W. W. Norton \& Company.

Saloviita, T. (2002). Challenging behaviour, and staff responses to it, in residential environments for people with intellectual disability in Finland. Journal of Intellectual \& Developmental Disability, 27(1), 21-30. doi:10.1080/1366825012010918.

Sameroff, A. (2009). The transactional model: How children and contexts shape each other. Washington DC, US: American Psychological Association.

Schaftenaar, P. (2015). De werkzame elementen van forensische sociotherapie: Een literatuurstudie. http://www.kfz.nl

Schein, E. H. (2004). Organizational culture and leadership (3rd ed.). San Francisco: Jossey-Bass.

Shermer, M. (2015). The moral arc: How science and reason lead humanity towards truth, justice, and freedom. New York: Henry Holt and Company.

Shiffrin, S. V. (2000). Paternalism, unconscionability doctrine, and accommodation. Philosophy \& Public Affairs, 29(3), 205-250.

Sine, D. M. (2008). The architecture of madness and the good of paternalism. Psychiatric Services, 59(9), 1060-1062. doi:10. 1176/appi.ps.59.9.1060.

Singer, T., Seymour, B., O’Doherty, J. P., Stephan, K. E., Dolan, R. J., \& Frith, C. D. (2006). Empathic neural responses are modulated by the perceived fairness of others. Nature, 439(7075), 466-469. doi:10.1038/nature04271.

Skinner, B. F. (1972). Punishment: A questionable technique. In R. H. Walters, J. Allan Cheyne, \& R. K. Banks (Eds.), Punishment: Selected readings (pp. 22-23). Middlesex, England: Penguin.

Smart, M. (2012). Unconditional space: Turning risk into resilience. Reclaiming Children and Youth, 21(1), 33-37.

Smith, M. L., \& Bowman, K. M. (2009). The restraint spiral: Emergent themes in the perceptions of the physical restraint of juveniles. Child Welfare, 88(3), 57-83.

Snow, N., \& Austin, W. J. (2009). Community treatment orders: The ethical balancing act in community mental health. Journal of Psychiatry and Mental Health Nursing, 16(12), 177-186. doi:10. 1016/j.mppsy.2009.09.009.

Sourander, A., Ellilä, H., Välimäki, M., \& Piha, J. (2002). Use of holding, restraints, seclusion and time-out in child and adolescent psychiatric in-patient treatment. European Child and Adolescent Psychiatry, 11(4), 162-167. doi:10.1007/s00787-002-0274-2.

Souverein, F. A., Van der Helm, G. H. P., \& Stams, G. J. J. M. (2013). "Nothing works" in secure residential youth care? Children and Youth Services Review, 35(12), 1941-1945. doi:10.1016/j.child youth.2013.09.010. 
Specter, D. (2006). Making prisons safe: Strategies for reducing violence. Journal of Law and Policy, 22, 125-134.

Sprague, J. R., Scheuermann, B., Wang, E., Michael Nelson, C., Jolivette, K., \& Vincent, C. (2013). Adopting and adapting PBIS for secure juvenile justice settings: Lessons learned. Education and Treatment of Children, 36(3), 121-134. doi:10.1353/etc. 2013.0031.

Stams, G. J. J. M., \& Van der Helm, G. H. P. (2016). What works in residential programs for aggressive and violent youth? Treating youth at risk for aggressive and violent behavior in (secure) residential care. Manuscript submitted for publication.

Steckley, L., \& Kendrick, A. (2008). Young people's experiences of physical restraint in residential care. Subtlety and complexity in policy and practice. In M. A. Nunno, M. Day, \& L. B. Bullard (Eds.), For your own safety: Examining the safety of high risk interventions for children and young people (pp. 3-24). Arlington, VA: Child Welfare Leagure of America.

Steffens, N. K., Schuh, S. C., Haslam, S. A., Pérez, A., \& Van Dick, R. (2015). "Of the group" and "for the group": How followership is shaped by leaders' prototypicality and group identification. European Journal of Social Psychology, 45(2), 180-190. doi:10.1002/ejsp.2088.

Steiner, H. (2002). Calibrating evil. The Monist, 85(2), 183-193.

Steiner, B., Butler, H. D., \& Ellison, J. M. (2014). Causes and correlates of prison inmate misconduct: A systematic review of the evidence. Journal of Criminal Justice, 42(6), 462-470. doi:10.1016/j.jcrimjus.2014.08.001.

Stone, D. T. (2001). Countertransference issues in adolescent residential settings. Journal of Child and Adolescent Group Therapy, 11(4), 147-157.

Strand, M., Benzein, E., \& Saveman, B. I. (2004). Violence in the care of adult persons with intellectual disabilities. Journal of Clinical Nursing, 13(4), 506-514. doi:10.1046/j.1365-2702. 2003.00848.x.

Strijbosch, E. L. L., Huijs, J. A. M., Stams, G. J. J. M., Wissink, I. B., Van der Helm, G. H. P., De Swart, J. J. W., \& Van der Veen, Z. (2015). The outcome of institutional youth care compared to non-institutional youth care for children of primary school age and early adolescence: A multi-level meta-analysis. Children and Youth Services Review, 58, 208-218. doi:10.1016/j.child youth.2015.09.018.

Suen, L. K. P., Lai, C. K. Y., Wong, T. K. S., Chow, S. K. Y., Kong, S. K. F., Ho, J. Y. L., et al. (2006). Use of physical restraints in rehabilitation settings: Staff knowledge, attitudes and predictors. Journal of Advanced Nursing, 55(1), 20-28. doi:10.1111/j.13652648.2006.03883.x.

Taxis, J. C. (2002). Ethics and praxis: Alternative strategies to physical restraint and seclusion in a psychiatric setting. Issues in Mental Health Nursing, 23(2), 157-170. doi:10.1080/ 016128402753542785.

Toch, H. (2008). Essay: Punitiveness as "Behavior Management". Criminal Justice and Behavior, 35(3), 388-397. doi:10.1177/ 0093854807309427.

Toch, H., \& Kupers, T. A. (2007). Violence in prisons, revisited. Journal of Offender Rehabilitation, 45(3/4), 1-28. doi:10.1300/ J076v45n03.

Tonkin, M. (2015). A review of questionnaire measures for assessing the social climate in prisons and forensic psychiatric hospitals. International Journal of Offender Therapy and Comparative Criminology,. doi:10.1177/0306624X15578834.

Tosey, P., Visser, M., \& Saunders, M. N. K. (2011). The origins and conceptualizations of "triple-loop" learning: A critical review.
Management Learning, 43(3), 291-307. doi:10.1177/ 1350507611426239.

Trice, H. M., \& Beyer, J. M. (1993). The cultures of work organisations. Englewood Cliffs, NJ: Prentice-Hall.

Vaes, J., \& Muratore, M. (2013). Defensive dehumanization in the medical practice: A cross-sectional study from a health care worker's perspective. British Journal of Social Psychology, 52(1), 180-190. doi:10.1111/bjso.12008.

Van der Helm, G. H. P., Beunk, L., Stams, G. J. J. M., \& Van der Laan, P. H. (2014). The relationship between detention length, living group climate, coping, and treatment motivation among juvenile delinquents in a youth correctional facility. The Prison Journal, 94(2), 260-275. doi:10.1177/0032885514524884.

Van der Helm, G. H. P., Boekee, I., Stams, G. J. J. M., \& Van der Laan, P. H. (2006). Fear is the key. Journal of Children's Services, 6(4), 248-263. doi:10.1108/17466661111190947.

Van der Helm, G. H. P., Klapwijk, M., Stams, G. J. J. M., \& Van der Laan, P. H. (2009). "What Works" for juvenile prisoners: The role of group climate in a youth prison. Journal of Children's Services, 4(1), 36-48.

Van der Helm, G. H. P., \& Schaftenaar, P. (2014). Eigen schuld, dikke bult? Leefklimaat en straf in de klinische psychiatrische zorg. Maandblad Geestelijke Volksgezondheid, 69(6), 28-34.

Van der Helm, G. H. P., \& Stams, G. J. J. M. (2012). Conflict and coping by clients and group workers in secure residential facilities. In K. T. I. Oei \& M. S. Groenhuijsen (Eds.), Progression in forensic psychiatry: About boundaries (pp. 158-177). Deventer: Kluwer.

Van der Helm, G. H. P., Stams, G. J. J. M., \& Van der Laan, P. H. (2011). Measuring group climate in a forensic setting. The Prison Journal, 19, 158-177.

Van der Helm, G. H. P., Van Miert, V. S. L. Nagtegaal, J., Stams, G. J. J. M., \& Beld, M. H. M. (2015). Rapportage Justitiële Jeugdinrichtingen 2014. Een onderzoek naar het leef-, werk- en leerklimaat binnen de Justitiële Jeugdinrichtingen [Report on Dutch Juvenile Justice Institutions 2014, research on living group, school and work climate]. The Hague.

Van Doeselaar, M., Sleegers, P., \& Hutschemaekers, G. (2008). Professionals' attitudes toward reducing restraint: The case of seclusion in The Netherlands. Psychiatric Quarterly, 79(2), 97-109. doi:10.1007/s11126-007-9063-x.

Viki, G. T., Fullerton, I., Raggett, H., Tait, F., \& Wiltshire, S. (2012). The role of dehumanization in attitudes toward the social exclusion and rehabilitation of sex offenders. Journal of Applied Social Psychology, 42(10), 2349-2367. doi:10.1111/j.15591816.2012.00944.x.

Waverly, J. (2011). Liberty or freedom? The difference is amazing. Retrieved August 10, 2015, from http://the-penultimate-word. com/2011/05/30/liberty-or-freedom-the-difference-is-amazing/

Wynn, R. (2003). Staff's attitudes to the use of restraint and seclusion in a Norwegian university psychiatric hospital. Nordic Journal of Psychiatry, 57(6), 453-459. doi:10.1080/08039480310003470.

Wynn, R. (2004). Psychiatric inpatients' experiences with restraint. The Journal of Forensic Psychiatry \& Psychology, 15(1), 124-144. doi:10.1080/14789940410001655187.

Wynn, R., Kvalvik, A.-M., \& Hynnekleiv, T. (2011). Attitudes to coercion at two Norwegian psychiatric units. Nordic Journal of Psychiatry, 65(2), 133-137. doi:10.3109/08039488.2010.513068.

Zimbardo, P. (2007). The Lucifer effect: How good people turn evil. London, UK: Random House. 